\title{
Supporting Information \\ Cobalt Oxide-Supported Pt Electrocatalysts: \\ Intimate Correlation between Particle Size, Electronic Metal-Support Interaction and Stability
}

\author{
Manon Bertram ${ }^{1}$, Carolin Pröss1 ${ }^{2,3}$, Michal Ronovský $^{4}$, Julius Knöppel ${ }^{2,3}$, Peter Matvija ${ }^{4}$, \\ Lukáš Fusek $^{4}$, Tomáš Skála ${ }^{4}$, Nataliya Tsud ${ }^{4}$, Maximilian Kastenmeierr1, Vladimír Matolín ${ }^{4}$, \\ Karl J. J. Mayrhofer², Viktor Johánek ${ }^{4}$, Josef Mysliveček ${ }^{4}$, Serhiy Cherevko ${ }^{2}$, \\ Yaroslava Lykhach ${ }^{1}$, Olaf Brummel ${ }^{1, *}$, Jörg Libuda ${ }^{1}$
}

${ }^{1}$ Interface Research and Catalysis, ECRC, Friedrich-Alexander-Universität Erlangen-Nürnberg, Egerlandstraße 3, 91058 Erlangen, Germany

${ }^{2}$ Helmholtz-Institute Erlangen-Nürnberg for Renewable Energy (IEK-11), Forschungszentrum Jülich GmbH, Egerlandstraße 3,91058 Erlangen, Germany

${ }^{3}$ Department of Chemical and Biological Engineering, Friedrich-Alexander-Universität ErlangenNürnberg, 91058 Erlangen, Germany

${ }^{4}$ Charles University, Faculty of Mathematics and Physics, Department of Surface and Plasma Science, V Holešovičkách 2, 18000 Prague, Czech Republic

* corresponding author: olaf.brummel@fau.de 


\section{Materials and Methods}

The data presented in this study was acquired at three different experimental setups. Highresolution synchrotron radiation photoelectron spectroscopy (SRPES) coupled with an electrochemical (EC) treatment was performed at the Materials Science Beamline (MSB), Elettra-Sincrotrone Trieste (Italy). Online inductively coupled plasma mass spectrometry (ICPMS) was carried out at the Helmholtz-Institute Erlangen-Nürnberg (Germany). The samples employed in the ICP-MS measurements were prepared in a UHV preparation chamber at the Friedrich-Alexander-University Erlangen-Nürnberg which is equipped with a dedicated transfer system. In addition, scanning tunneling microscopy (STM) images were recorded at the Charles University, Prague (Czech Republic).

\subsection{Scanning Tunneling Microscopy}

Experimental Setup. The morphology of the $\mathrm{Co}_{3} \mathrm{O}_{4}(111)$ substrate and the $\mathrm{Pt} / \mathrm{Co}_{3} \mathrm{O}_{4}(111)$ model catalysts was analyzed at a UHV setup which is operated at a base pressure of $3 \times 10^{-10}$ mbar. The system comprises preparation tools, e.g. an ion gun, metal evaporators, a quartz crystal microbalance (QCM), and a low energy electron diffraction (LEED) optics, X-ray photoelectron spectroscopy (XPS), and scanning tunneling microscopy (STM) for analysis.

Preparation of $\mathrm{Co}_{3} \mathrm{O}_{4}(111)$ thin films and Pt particles. The $\mathrm{Co}_{3} \mathrm{O}_{4}(111)$ thin films were prepared on $\operatorname{Ir}(100)$ single crystals employing adapted methods based on the procedure of Heinz and Hammer. ${ }^{1-2}$ We slightly modified the method with respect to the different UHV systems. For STM analysis, the $\operatorname{Ir}(100)$ substrate (MaTecK) was cleaned by repeating cycles of ion bombardment and annealing at $1330 \mathrm{~K}$ to obtain the $\operatorname{Ir}(100)-(5 \times 1)$ surface structure. Annealing in $\mathrm{O}_{2}$ (Linde $5.0,5 \times 10^{-7} \mathrm{mbar}$ ) at $1270 \mathrm{~K}$ yielded the $\operatorname{Ir}(100)-(2 \times 1)$ oxygen terminated surface. Co (Alfa Aesar, $99.995 \%$ ) was then deposited from an electron-heated Ta crucible in a reactive oxygen atmosphere $\left(1.5 \times 10^{-6} \mathrm{mbar}\right)$ at $300 \mathrm{~K}$ with a deposition rate of $0.7 \mathrm{ML} / \mathrm{min}$. Here, a monolayer (ML) was defined as the vertical $4.7 \AA$ repeat unit of the $\mathrm{Co}_{3} \mathrm{O}_{4}(111)$ spinel structure. After deposition, the sample was first annealed in $\mathrm{O}_{2}\left(2 \times 10^{-6} \mathrm{mbar}\right)$ at $680 \mathrm{~K}$ for $60 \mathrm{~min}$ and, subsequently, annealed in UHV at $720 \mathrm{~K}$. The structure was verified by LEED and the film thickness, $5.0 \mathrm{~nm}$, determined by QCM and the attenuation of the Ir $4 \mathrm{f}$ signal in XPS. Pt NPs were deposited by PVD of Pt (Safina, 99.99 \%) at $300 \mathrm{~K}$ in UHV. The nominal thickness of the Pt film was determined by QCM. We prepared two samples with an amount of 0.3 and $4.5 \AA \mathrm{Pt}(0.14$ and $2.05 \mathrm{ML})$.

Measurement procedure. STM measurements were performed with electrochemically etched $\mathrm{W}$ tips and employing sample voltages from -2 to $-3 \mathrm{~V}$ and tunneling currents between $50-300 \mathrm{pA}$. 


\subsection{Synchrotron Radiation Photoelectron Spectroscopy Coupled with an EC Cell}

Experimental setup. The MSB with a bending magnet source provided synchrotron light in the energy range of 21-1000 eV. The UHV end-station, with a base pressure of $2 \times 10^{-10} \mathrm{mbar}$, was equipped with a multichannel electron energy analyzer (Specs Phoibos 150), a rear view LEED optics, an ion gun $\left(\mathrm{Ar}^{+}\right)$, a gas dosing system, and two electron beam evaporators for the deposition of Co and Pt metals. Furthermore, a dedicated EC flow cell was coupled to the analysis chamber via two buffer chambers and a transfer chamber enabling a transfer of the sample between the analysis chamber and the EC cell without exposure to air.

The EC cell. The EC setup for performing ex situ emersion synchrotron radiation photoelectron spectroscopy (SRPES) at the MSB beamline is depicted in Figure S1. The EC cell was separated from the transfer chamber by a gate valve and consists of a glass housing which is divided into two compartments. The lower compartment comprises an inlet for the electrolyte, an inlet for the counter electrode (CE; Au wire, Hauner, $99.999 \%$ ), and an inlet housing the reference electrode ( $\mathrm{RE}$; commercial $\mathrm{Ag} / \mathrm{AgCl}$, ALS, $3 \mathrm{M} \mathrm{NaCl}, 0.195 \mathrm{~V}_{\mathrm{NHE}}$ ) which is separated from the lower compartment via a stop cock. The two compartments are connected by a capillary through which the electrolyte is pumped. The upper compartment houses an outlet for the electrolyte, a gas inlet for establishing an Ar atmosphere, and a shower for rinsing the sample with ultrapure water after the EC treatment. The electrolyte flow was controlled via inlet and outlet valves. The sample used as working electrode (WE) was mounted on a PTFE stick which is connected to a $\mathrm{x}-, \mathrm{y}-$, and z-translation stage. Potential control was established by means of a commercial potentiostat (Gamry, Reference 600).

Prior to mounting the EC flow cell to the transfer stage all glass and PTFE equipment and all metal wires were thoroughly cleaned by overnight storage in a sulfuric acid solution (98\%, Merck, EMSURE) containing NOCHROMIX (Sigma Aldrich). The equipment was rinsed with ultrapure water (MilliQ synergy UV, $18.2 \mathrm{M} \Omega \mathrm{cm}$ at $25^{\circ} \mathrm{C},<5 \mathrm{ppb}$ TOC) five times and boiled in ultrapure water three times. PFA tubes were rinsed with ultrapure water and cleaned from the outside with isopropanol. 

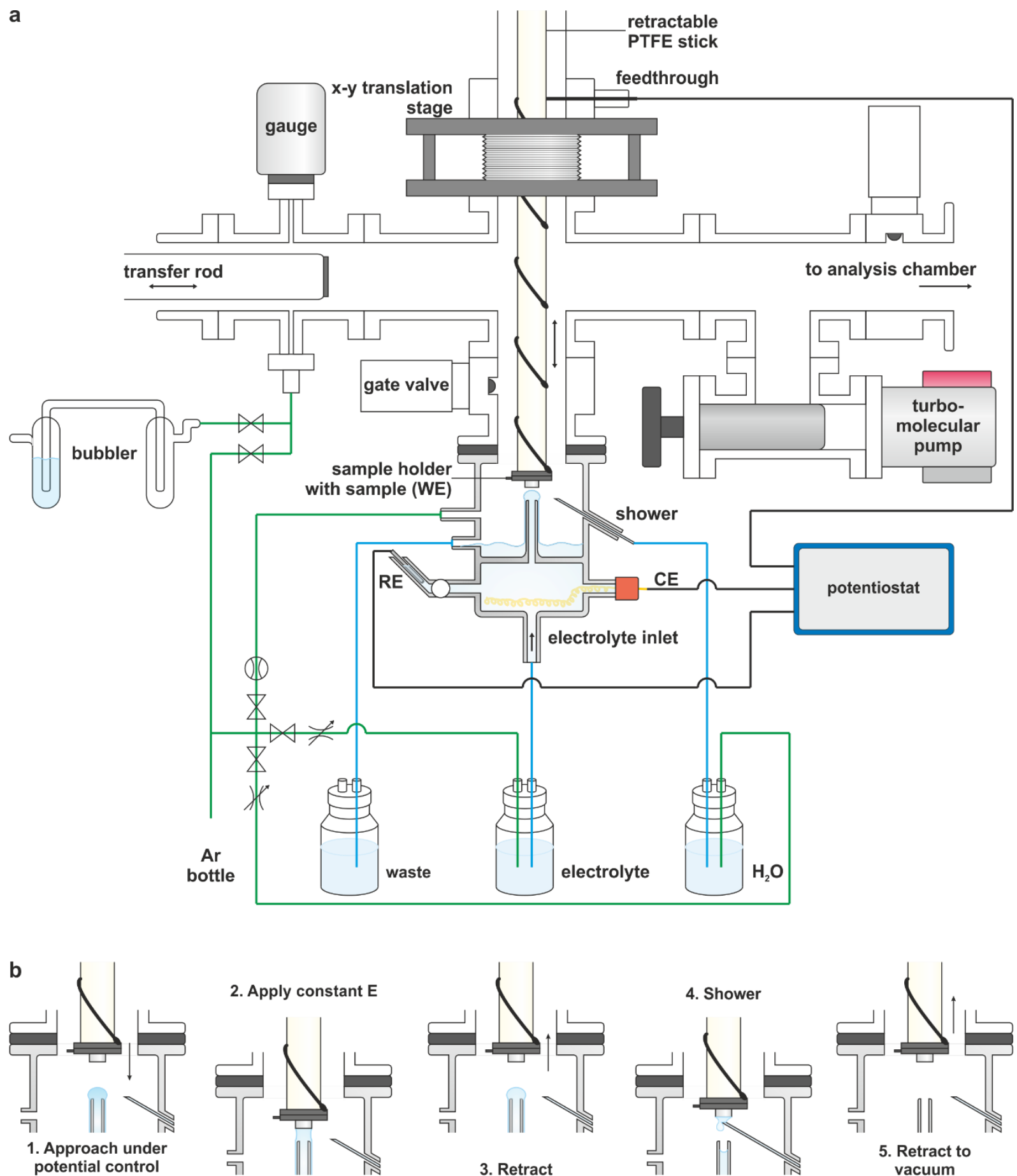

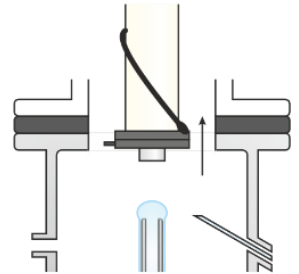

3. Retract
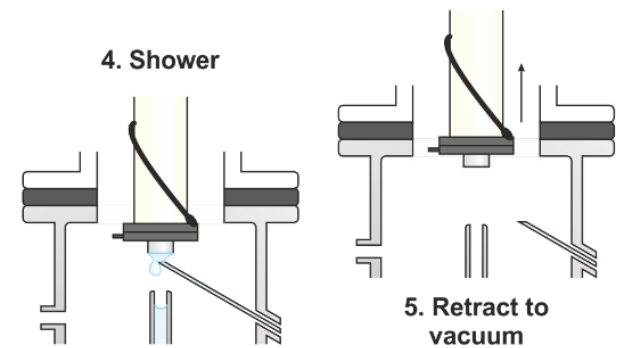

Figure S1 Schematic drawing of the ex situ emersion SRPES setup at the Materials Science Beamline, Elettra-Sincrotrone Trieste, Italy (a). Experimental protocol before, during, and after the electrochemical treatment (b). See text for more details.

Preparation of $\mathrm{CO}_{3} \mathrm{O}_{4}(111)$ thin films and Pt nanoparticles. In the following, the preparation of the oxide film at the MSB is described, based on the procedure of Heinz and Hammer. ${ }^{1-2}$ The $\operatorname{Ir}(100)$ single crystal (MaTecK, $99.99 \%$, depth of roughness $<0.01 \mu \mathrm{m}$, accuracy of orientation $<0.1^{\circ}$ ) was cleaned by repetitious $\mathrm{Ar}^{+}$bombardment (SIAD $6.0,2 \times 10^{-6} \mathrm{mbar}, 1.0 \mathrm{kV}, 300 \mathrm{~K}$ ) and consecutive annealing cycles (UHV, $1300 \mathrm{~K}, 3 \mathrm{~min}$; followed by annealing in $\mathrm{O}_{2}$, SIAD 
5.0, $1 \times 10^{-7} \mathrm{mbar}, 1273 \mathrm{~K}, 3 \mathrm{~min}$ and subsequent cooling in $\left.\mathrm{O}_{2}\right)$. The $\operatorname{Ir}(100)-(5 \times 1)$ reconstructed surface was obtained by annealing the sample at $1300 \mathrm{~K}$ in UHV. The absence of carbon or other contaminants was checked by X-ray photoelectron spectroscopy. Successive annealing of the surface at $1273 \mathrm{~K}$ in $\mathrm{O}_{2}$ atmosphere $\left(1 \times 10^{-7} \mathrm{mbar}\right)$ and cooling below $350 \mathrm{~K}$ in $\mathrm{O}_{2}$ yielded the $\operatorname{Ir}(100)-(2 \times 1) \mathrm{O}$ reconstruction as confirmed by LEED. Then, cobalt (Goodfellow, $99.99 \%$ ) was deposited by physical vapor deposition (PVD) in a reactive $\mathrm{O}_{2}$ atmosphere $\left(2.5 \times 10^{-6} \mathrm{mbar}\right)$ at $273 \mathrm{~K}$. An ordered, epitaxial film was formed by annealing in $\mathrm{O}_{2}\left(1 \times 10^{-6} \mathrm{mbar}\right)$ at $523 \mathrm{~K}$ for $3 \mathrm{~min}$ and at $603 \mathrm{~K}$ for $7 \mathrm{~min}$ followed by subsequent annealing in $\mathrm{UHV}$ at $603 \mathrm{~K}$ for $3 \mathrm{~min}$ and at $680 \mathrm{~K}$ for another $3 \mathrm{~min}$. The structure of the $\mathrm{Co}_{3} \mathrm{O}_{4}(111)$ film was verified by LEED. The preparation procedure yielded films of $5.5 \mathrm{~nm}$ thickness as determined from the attenuation of the $\operatorname{Ir} 4 f_{7 / 2}$ intensity.

Pt nanoparticles were deposited by PVD of Pt (Goodfellow, 99.99 \%) at $300 \mathrm{~K}$ in UHV. The nominal thickness of the Pt film was determined from the attenuation of the Co $2 p$ intensity. We prepared two samples with layer thicknesses of $3.6 \AA$ and $0.3 \AA \mathrm{Pt}$ corresponding to nominal Pt monolayers (ML) of 1.64 and 0.14 ML.

Measurement procedure and data treatment. The EC measurements were carried out in 0.1 M sodium phosphate buffer $\left(\mathrm{Na}_{2} \mathrm{PO}_{4}\right.$, Merck, Suprapur, $99.99 \%$; $\mathrm{NaOH}$, Sigma Aldrich, $99.99 \%)$ at $\mathrm{pH} 10$. Prior to the start of the experiment the electrolyte was thoroughly degassed with Ar. The EC treatment was performed by establishing a constant electrolyte flow at the top of the capillary in the EC cell. Subsequently, the sample was approached to the top of the capillary under potential control and, upon contact with the electrolyte, a meniscus was formed. The sample was objected to a chosen constant potential for $3 \mathrm{~min}\left(0.5-1.5 \mathrm{~V}_{\mathrm{RHE}}\right)$. After $3 \mathrm{~min}$ the sample was retracted, rinsed with degassed ultrapure water, and dried in the transfer chamber before transfer to the analysis chamber (see also Figure S1 (b)).

Core level spectra were acquired with photon energies of $180(\mathrm{Pt} 4 \mathrm{f}), 380(\mathrm{Pt} 4 \mathrm{f}), 650(\mathrm{Pt} 4 \mathrm{f})$, and $930 \mathrm{eV}$ (Co 2p). The binding energies were calibrated with respect to the Fermi level. All spectra were recorded at constant pass energy and at an emission angle of the photoelectrons of $0^{\circ}$ with respect to the sample normal. The total spectral resolution was $200 \mathrm{meV}(\mathrm{hv}=180 \mathrm{eV})$, $380 \mathrm{meV}(\mathrm{h} v=380 \mathrm{eV}), 650 \mathrm{meV}(\mathrm{h} v=650 \mathrm{eV})$, and $1 \mathrm{eV}(\mathrm{h} v=930 \mathrm{eV})$. All SRPES data were processed employing the KolXPD fitting software. ${ }^{3}$ The spectral components in the Pt $4 \mathrm{f}$ spectra were fitted with an asymmetric Doniach-Šunjić function convoluted with a Gaussian profile. 


\subsection{Online Inductively Coupled Plasma-Mass Spectrometry}

Experimental setup. The samples for online ICP-MS experiments were prepared in a dedicated UHV preparation setup that has been described in detail elsewhere. ${ }^{4-5}$ Briefly, the system comprises a LEED optics, a quartz crystal microbalance, an ion gun, electron beam evaporators, a gas dosing system, and a transfer stage.

A detailed description of the online ICP-MS setup is presented in the literature. ${ }^{6-7}$ Briefly, an EC scanning flow cell (SFC) is coupled to an ICP-MS for the downstream analysis of dissolved species. The SFC comprises two channels which cross to form an opening enclosed by a silicon sealing to prevent leaking of the electrolyte. The inlet channel houses the counter electrode, while the reference electrode is installed downstream. The flow rate of the online ICP-MS (Perkin Elmer NexION 300X) was $205 \mathrm{~mL} \mathrm{~min}{ }^{-1} .{ }^{187} \mathrm{Re}$ and ${ }^{74} \mathrm{Ge}$ served as internal standards. The contact area of the flow cell was $0.035 \mathrm{~cm}^{2}$. The sample served as working electrode, while a saturated $\mathrm{Ag} / \mathrm{AgCl}$ electrode (Metrohm, $3 \mathrm{M} \mathrm{KCl}$ ) and a glassy carbon rod (HTW) were used as reference and counter electrode, respectively. The potential was controlled by a commercial potentiostat (Gamry, Reference 600) and the system operated by LabVIEW routines.

Sample preparation. $\mathrm{Co}_{3} \mathrm{O}_{4}(111)$ thin films were also prepared by an adapted method based on the procedure of Heinz and Hammer. ${ }^{1-2}$ For a detailed description of the preparation used for the online ICP-MS measurements we refer to our previous publication. ${ }^{8} \mathrm{Pt}$ particles were deposited by PVD of Pt (Alfa Aesar, $99.95 \%$, rod of $1 \mathrm{~mm}$ in diameter) at $300 \mathrm{~K}$. The deposition rate for Co was calibrated prior to the preparation by means of a quartz crystal microbalance. The deposition rate for Pt was calibrated prior to the preparation by means of ex situ XPS.

Measurement procedure and data treatment. The EC measurements were performed in $0.05 \mathrm{M}$ sodium phosphate buffer $\left(\mathrm{Na}_{2} \mathrm{PO}_{4}\right.$, Merck, Suprapur, $99.99 \%$; $\mathrm{NaOH}$, Sigma Aldrich, $99.99 \%)$ at $\mathrm{pH} 10$. The WE was brought into contact with the SFC under potential control. Different experimental procedures were applied and the measurement protocols were repeated $2-3$ times on the same sample using different spots for analysis. We mimicked the ex situ emersion SRPES procedure by applying a step potential sequence between 0.5 and $1.5 \mathrm{~V}_{\mathrm{RHE}}$ ( 3 min per potential step). Further, we performed cyclic voltammetry (CV) between 0.5 and $1.5 \mathrm{~V}_{\mathrm{RHE}}(5 \mathrm{mV} / \mathrm{s})$ while we recorded the dissolution of ${ }^{59} \mathrm{Co}$ and ${ }^{195} \mathrm{Pt}$. The ICP-MS data were calibrated and presented after background correction. Dissolved quantities are expressed as mass per area per time $\left(\mathrm{pg} \mathrm{cm}^{-2} \mathrm{~s}^{-1}\right)$. In addition, the dissolution rate is normalized to the surface atom density of Co and $\mathrm{Pt}$, respectively. 


\section{Nanoparticle Sizes and Densities of Surface Atoms}

\subsection{Pt Nanoparticle Sizes and Available Surface Atoms}

The density of Pt nanoparticles was obtained from the evaluation of the STM images. Taking into account the bulk density of $\operatorname{Pt}\left(21.45 \mathrm{~g} \mathrm{~cm}^{-3}\right)$ and the nominal thickness of the Pt layer after evaporation, the average number of $\mathrm{Pt}$ atoms per particle could be calculated. The average number of $\mathrm{Pt}$ atoms per particle is related to the volume of one nanoparticle via the bulk density of Pt. Assuming a hemispherical particle shape, we calculated the average nanoparticle diameter (see Table 1). Note that a 2.05 ML Pt sample was prepared for STM, while 1.64 ML Pt were prepared for ex situ emersion SRPES and online ICP-MS. To calculate the average number of Pt atoms per particle and the particle diameter for 1.64 ML Pt, the same particle density as obtained for 2.05 ML Pt was assumed.

The number of available surface Pt atoms was calculated by subtracting the number of subsurface Pt atoms per particle, i.e. the number of $\mathrm{Pt}$ atoms located in the interior of a NP, from the total number of $\mathrm{Pt}$ atoms per particle. The number of subsurface $\mathrm{Pt}$ atoms in the interior of a NP was obtained by subtracting the diameter of one Pt atom $(2 \times$ the covalent radius of Pt, $136 \mathrm{pm}$ ) from the average nanoparticle radius. This reduced radius was then used to calculate the hemispherical volume and, consecutively, the number of Pt atoms below the layer of surface $\mathrm{Pt}$ atoms in the nanoparticle. Relating the number of surface $\mathrm{Pt}$ atoms per particle to the density of Pt particles on the surface yielded the total density of available Pt atoms at the particle surface (see Table 2). After a conversion to mass per area this value was then used to normalize the integrated online ICP-MS data. Furthermore, the Pt dispersion (surface atoms/total atoms) was calculated yielding values of 0.5 (2.05 ML Pt), 0.54 (1.64 ML Pt), and 1 (0.14 ML Pt).

Note that all parameters determined here are based on the nominal thickness of the Pt layer. As the nominal thickness of the Pt layer was calibrated by means of XPS or QCM and the same (averaged) size was assumed for all NPs, the calculated parameters can only be estimated.

Table 1 Average Pt NP size calculated from the density of Pt NPs.

\begin{tabular}{ccccc}
$\begin{array}{c}\text { Amount of } \\
\text { deposited Pt }[\mathrm{ML}]\end{array}$ & $\begin{array}{c}\text { Nominal Pt } \\
\text { thickness }[\AA]\end{array}$ & $\begin{array}{c}\text { NP density } \\
{\left[\mathrm{cm}^{-2}\right]}\end{array}$ & $\begin{array}{c}\text { Average number of } \\
\text { Pt atoms per NP }\end{array}$ & $\begin{array}{c}\text { Average NP } \\
\text { size [nm] }\end{array}$ \\
\hline \hline 2.05 & 4.5 & $1 \times 10^{13}$ & $\sim 298$ & $\sim 2.6$ \\
1.64 & 3.6 & $1 \times 10^{13}$ & $\sim 238$ & $\sim 2.4$ \\
0.14 & 0.3 & $4 \times 10^{13}$ & $\sim 5-6$ & $\sim 0.7$
\end{tabular}


Table 2 Density of available Pt surface atoms.

\begin{tabular}{ccccc}
$\begin{array}{c}\text { Amount of } \\
\text { deposited Pt } \\
{[\mathrm{ML}]}\end{array}$ & $\begin{array}{c}\text { Average } \\
\mathrm{NP}_{\text {subsurface }}\end{array}$ & $\begin{array}{c}\text { Average number } \\
\text { of } \mathrm{Pt}_{\text {subsurface }} \text { atoms } \\
\text { radius [nm] }\end{array}$ & $\begin{array}{c}\text { Average number } \\
\text { of } \mathrm{Pt}_{\text {surface }} \text { atoms } \\
\text { per NP }\end{array}$ & $\begin{array}{c}\text { Density of } \\
\mathrm{Pt}_{\text {surface }} \text { atoms } \\
{\left[\mathrm{cm}^{-2}\right]}\end{array}$ \\
\hline \hline 2.05 & $\sim 1.028$ & $\sim 151$ & $\sim 147$ & $1.47 \times 10^{15}$ \\
1.64 & $\sim 0.928$ & $\sim 111$ & $\sim 127$ & $1.27 \times 10^{15}$ \\
0.14 & $\sim 0.063$ & “0.03” & $\sim 5-6$ & $1.96 \times 10^{14}$
\end{tabular}

\subsection{Density of Co Surface Atoms}

The $\mathrm{Co}_{3} \mathrm{O}_{4}(111)$ film is terminated by $\mathrm{Co}$ atoms that would correspond to $\mathrm{Co}^{2+}$ in the bulk crystal (see STM image Figure 1a). The distance of $\mathrm{Co}^{2+}$ atoms in the surface layer equals $5.72 \AA$, spanning a surface unit cell of $28.3 \AA^{2} .{ }^{9}$ With this value, we obtain a density of surface $\mathrm{Co}^{2+}$ atoms of $3.5 \times 10^{14} \mathrm{~cm}^{-2}$. This value is also used to define $1 \mathrm{ML}$ of cobalt for conversion of the Co dissolution rate between mass per area and MLs and it was employed to normalize the integrated online ICP-MS data. 


\section{EC Photoelectron Spectroscopy}

\subsection{Growth Mode of Pt Particles}

Previously, we studied the stepwise growth of Pt particles on $\mathrm{Co}_{3} \mathrm{O}_{4}(111)$ via SRPES in detail. ${ }^{10-}$

${ }^{11}$ Briefly, the spin-orbit doublet attributed to partially oxidized $\mathrm{Pt}^{\delta+}$ dominated the $\mathrm{Pt} 4 \mathrm{f}$ spectra at low coverage. As the binding energy of $\mathrm{Pt}^{\delta^{+}}$remained nearly constant, we assume that particles initially grow in form of nearly two-dimensional aggregates. Note that, in our previous studies, we did not perform depth profiling experiments. In consequence, we did not monitor the formation of $\mathrm{Pt}^{4+}$ species. With increasing coverage, the spin-orbit doublet of metallic $\mathrm{Pt}^{0}$ develops and becomes the main contribution above $0.5 \mathrm{ML} \mathrm{Pt}$. While the $\mathrm{Pt}^{0}$ contribution increased with increasing coverage, the $\mathrm{Pt}^{\delta+}$ signal was attenuated. This behavior indicates the formation of 3-dimensional particles with metallic $\mathrm{Pt}^{0}$ covering the $\mathrm{Pt}^{\delta+}$ species.

\subsection{Pt Depth Profiling}

In order to obtain information on the location of oxidized Pt species and, thereby, on the oxidation mechanism, we performed depth profiling experiments employing excitation energies
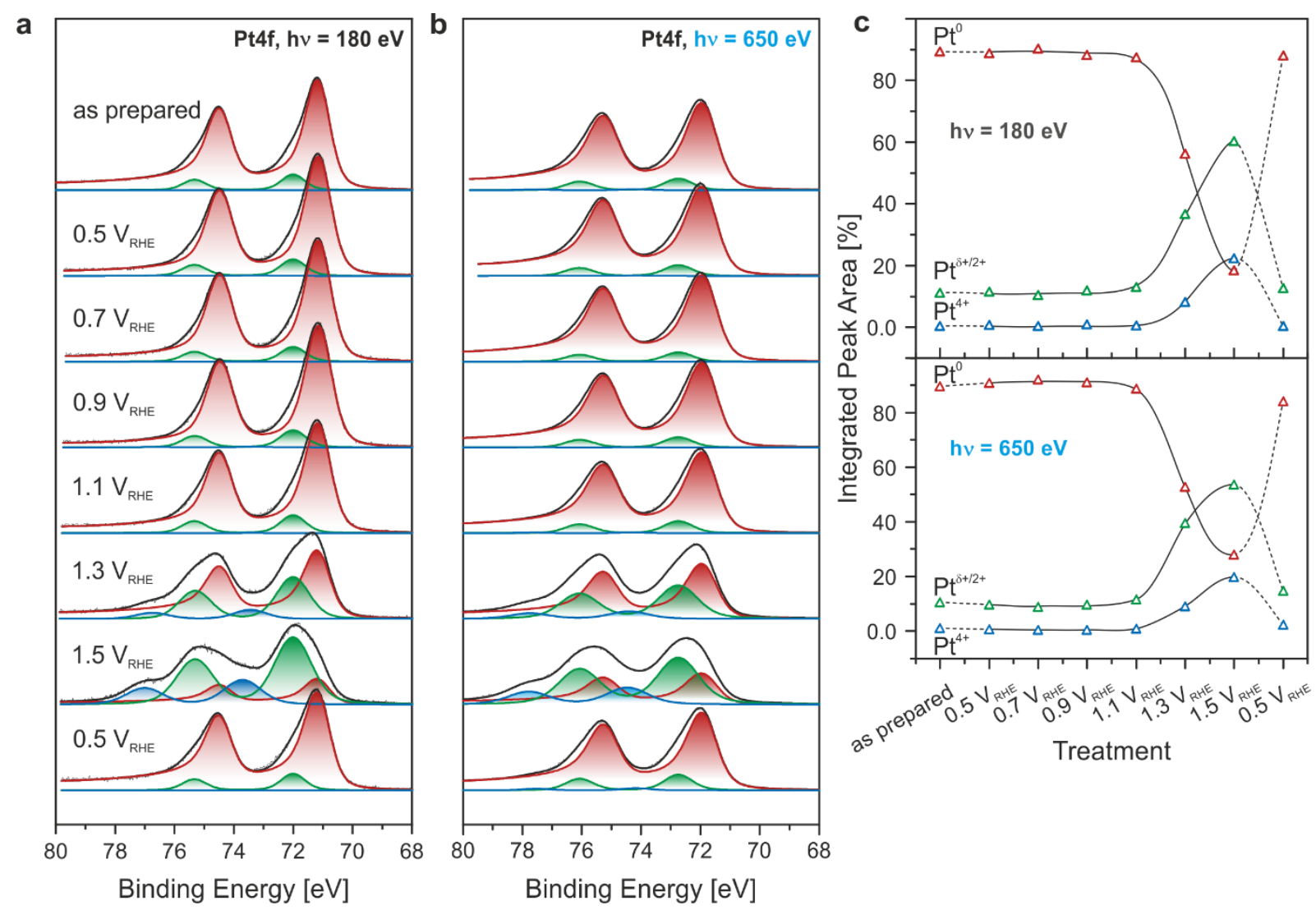

Figure S2 Pt $4 \mathrm{f}$ core level spectra of conventional Pt NPs (1.64 ML Pt) on $\mathrm{Co}_{3} \mathrm{O}_{4}(111)$ before and after electrochemical exposure in $0.1 \mathrm{M}$ sodium phosphate buffer at $\mathrm{pH}=10$ obtained at $180 \mathrm{eV}$ (a) and $650 \mathrm{eV}$ (b). Integrated peak area for the different Pt components (c). $\mathrm{Pt}^{0}$ marked in red, $\mathrm{Pt}^{\delta^{+/ 2+}}$ in green, and $\mathrm{Pt}^{4+}$ in blue. 


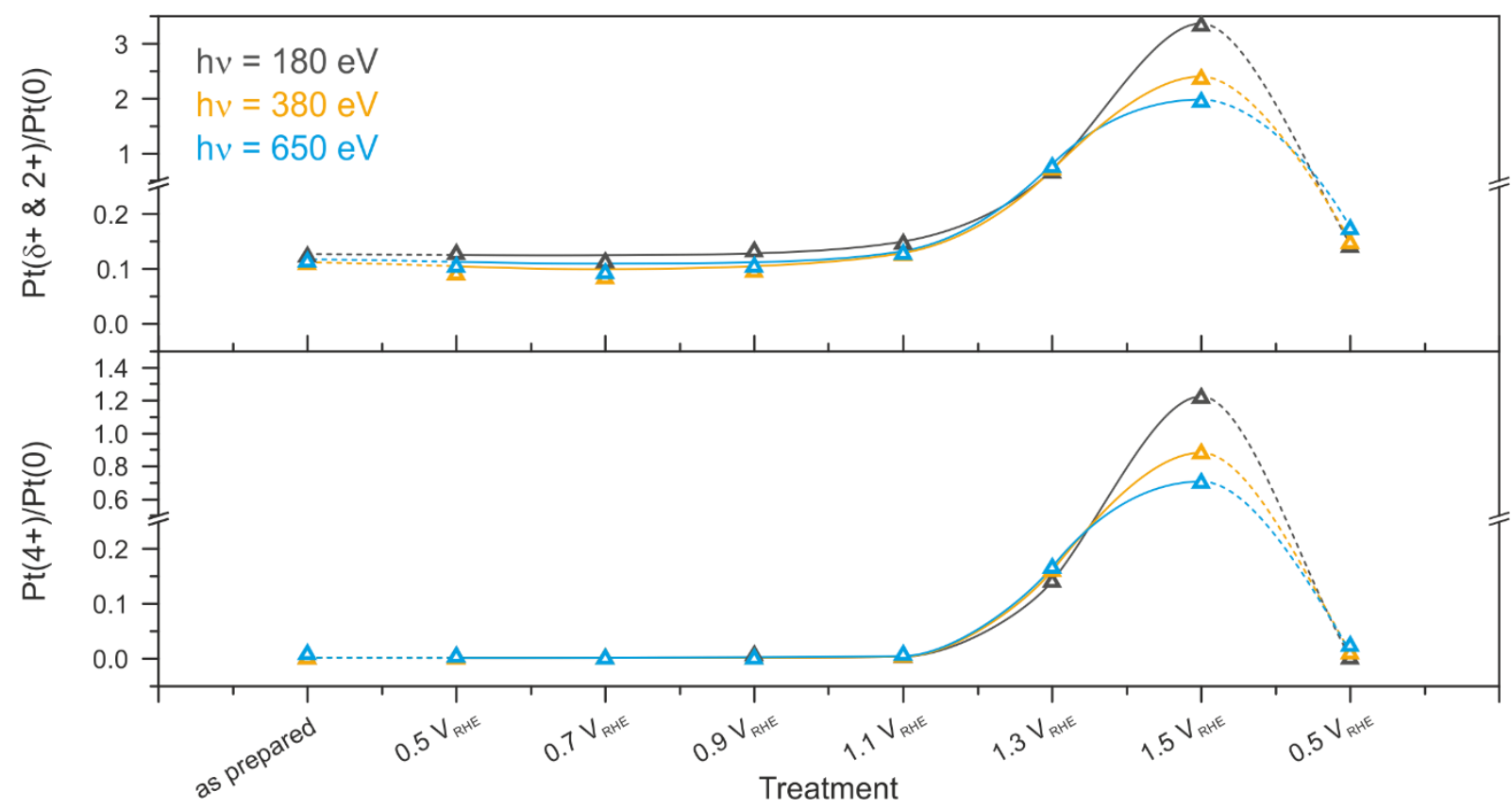

Figure S3 Ratios of $\mathrm{Pt}^{\delta^{+/ 2+}}$ (upper panel) and $\mathrm{Pt}^{4+}$ (lower panel) to metallic $\mathrm{Pt}^{0}$ for conventional Pt NPs (1.64 ML) on $\mathrm{Co}_{3} \mathrm{O}_{4}(111)$ obtained by integration of the fitted Pt $4 \mathrm{f}$ core level spectra. of 180,380 , and $650 \mathrm{eV}$ to record the Pt $4 \mathrm{f}$ core level spectra. These photon energies correspond to information depths of approximately $3.8,5.6$, and $8.2 \AA$, respectively. ${ }^{12}$ The data obtained at $380 \mathrm{eV}$ are presented in Figure 2 of the main letter, while the complete set of spectra recorded at 180 and $650 \mathrm{eV}$ is displayed in Figure S2 for conventional NPs. Evaluation of the data by

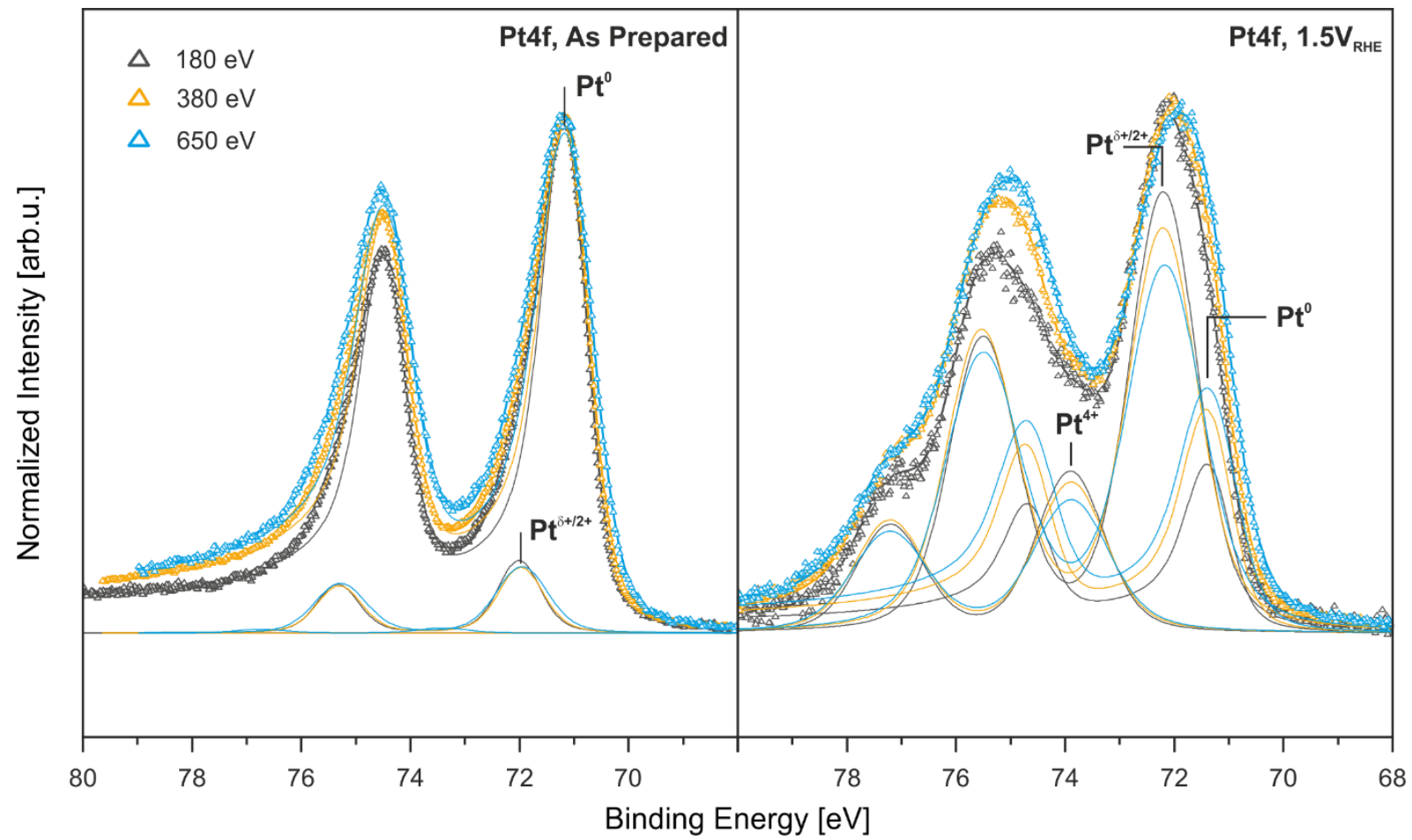

Figure S4 Comparison of the Pt $4 \mathrm{f}$ core level spectra and their respective fits obtained for conventional Pt NPs (1.64 ML) after preparation (left panel) and after EC treatment at 1.5 $\mathrm{V}_{\text {RHE. }}$ 
peak integration gives the ratios of oxidized $\mathrm{Pt}^{4+}$ and $\mathrm{Pt}^{\delta^{+}}$or $\mathrm{Pt}^{2+}$ to metallic $\mathrm{Pt}^{0}$, respectively, which are presented in Figure S3. Before applying oxidizing potentials, the ratio of oxidized to metallic Pt species is nearly independent of the excitation energy. Only at the highest potential, i.e. 1.5 $\mathrm{V}_{\mathrm{RHE}}$, a large difference is observed (see also Figure $\mathrm{S} 4$ comparing the Pt $4 \mathrm{f}$ spectra of the UHV prepared sample and after emersion at $1.5 \mathrm{~V}_{\mathrm{RHE}}$ ). With decreasing excitation energy, the ratio of oxidized to metallic Pt species increases. That means that the ratio shifts in favor of the oxidized species at the most surface sensitive, lowest excitation energy. This behavior is in line with the formation of $\mathrm{PtO}$ and $\mathrm{PtO}_{2}$ surface oxides at increasing potentials. ${ }^{13-14}$

In Figure S5 we show the Pt 4f spectra recorded with photon energies of 180 and $650 \mathrm{eV}$ for subnanometer $\mathrm{Pt}$ aggregates. Peak integration gives the ratio of $\mathrm{Pt}^{4+}$ species to partially oxidized $\mathrm{Pt}^{\delta+}$ or $\mathrm{Pt}^{2+}$ species that is presented in Figure S6. While the data obtained at $180 \mathrm{eV}$ is difficult to fit due to the high level of noise (see Figure S6 (b)), a trend is nevertheless visible: The ratio of fully oxidized $\mathrm{Pt}^{4+}$ to partially oxidized $\mathrm{Pt}^{\delta^{+}}$is always lowest at the lowest, most surface sensitive photon energy. This implies that $\mathrm{Pt}^{4+}$ species are located and, especially at oxidizing potentials, also formed in the subsurface region of the model electrocatalyst.
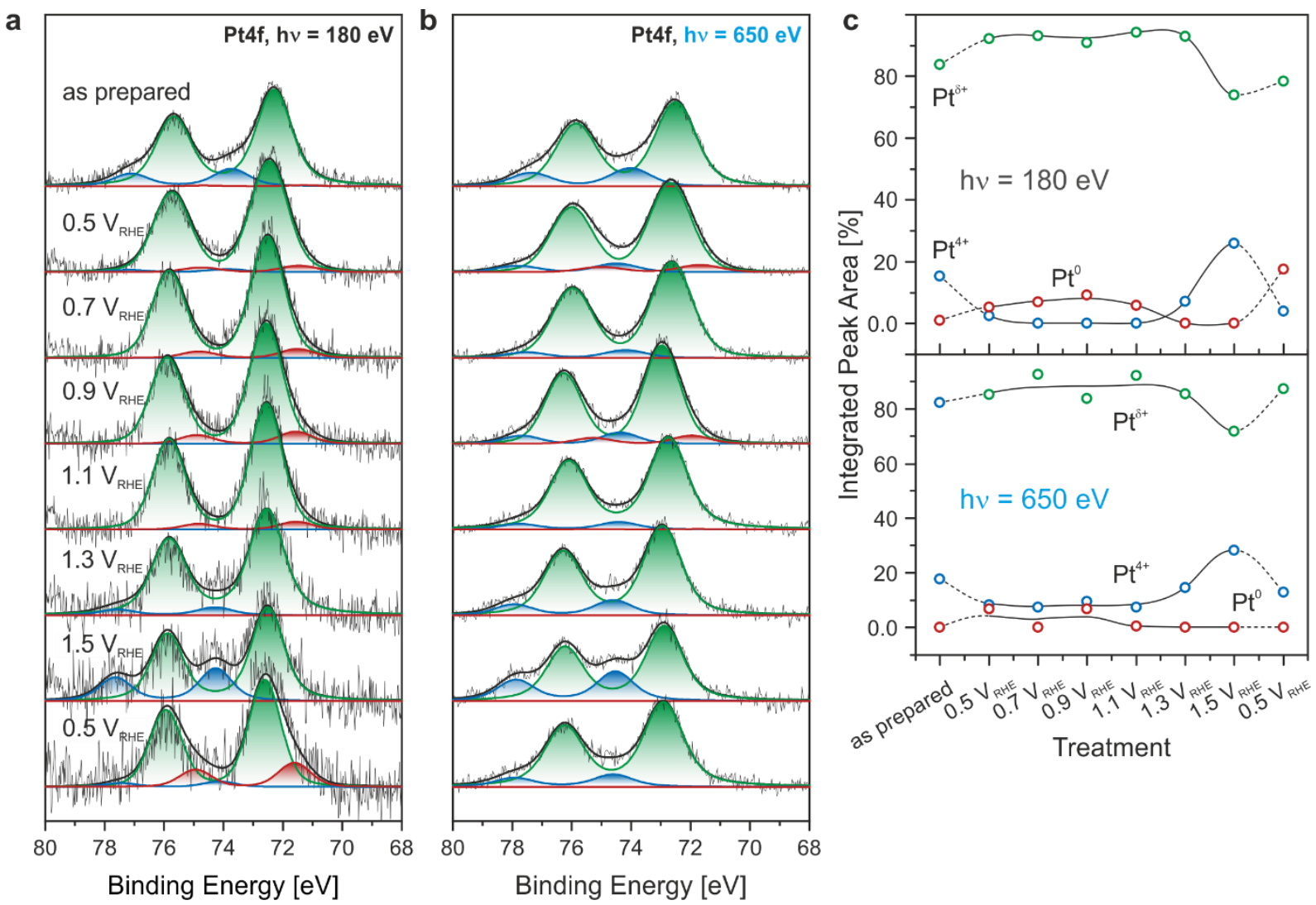

Figure S5 Pt $4 \mathrm{f}$ core level spectra of subnanometer Pt aggregates (0.14 ML Pt) on $\mathrm{Co}_{3} \mathrm{O}_{4}(111)$ before and after electrochemical exposure in $0.1 \mathrm{M}$ sodium phosphate buffer at $\mathrm{pH}=10$ obtained at $180 \mathrm{eV}$ (a) and $650 \mathrm{eV}$ (b). Integrated peak area for the different Pt components (c). $\mathrm{Pt}^{0}$ marked in red, $\mathrm{Pt}^{\delta^{+}}$in green, and $\mathrm{Pt}^{4+}$ in blue. 


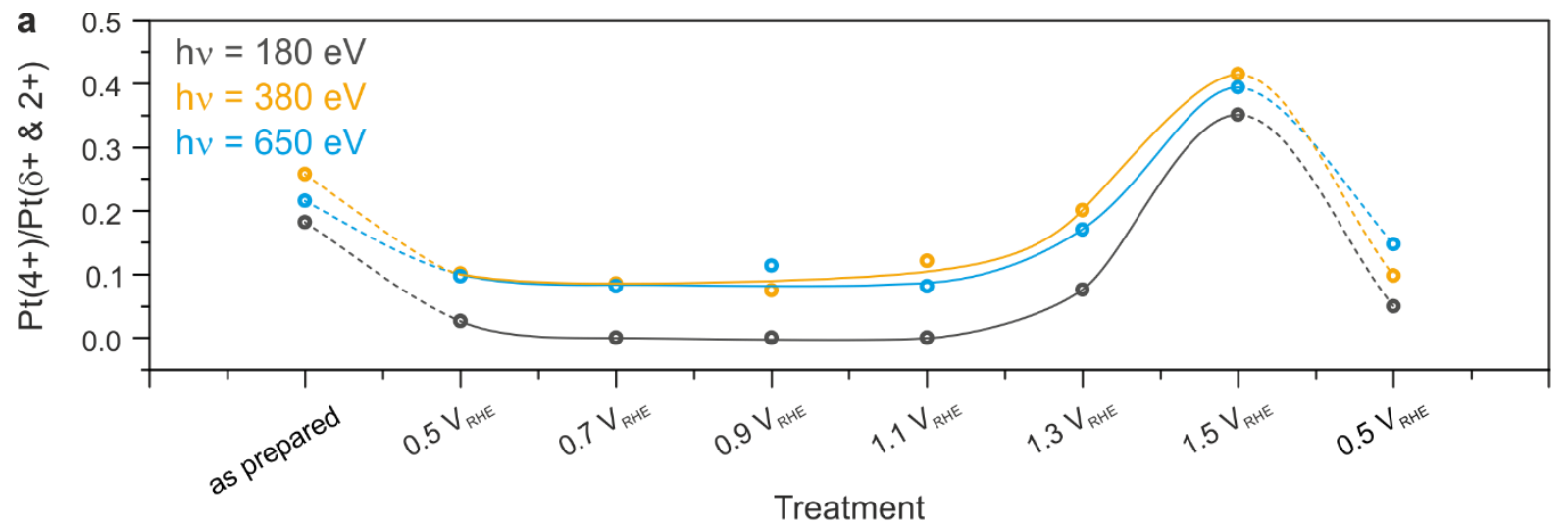

b

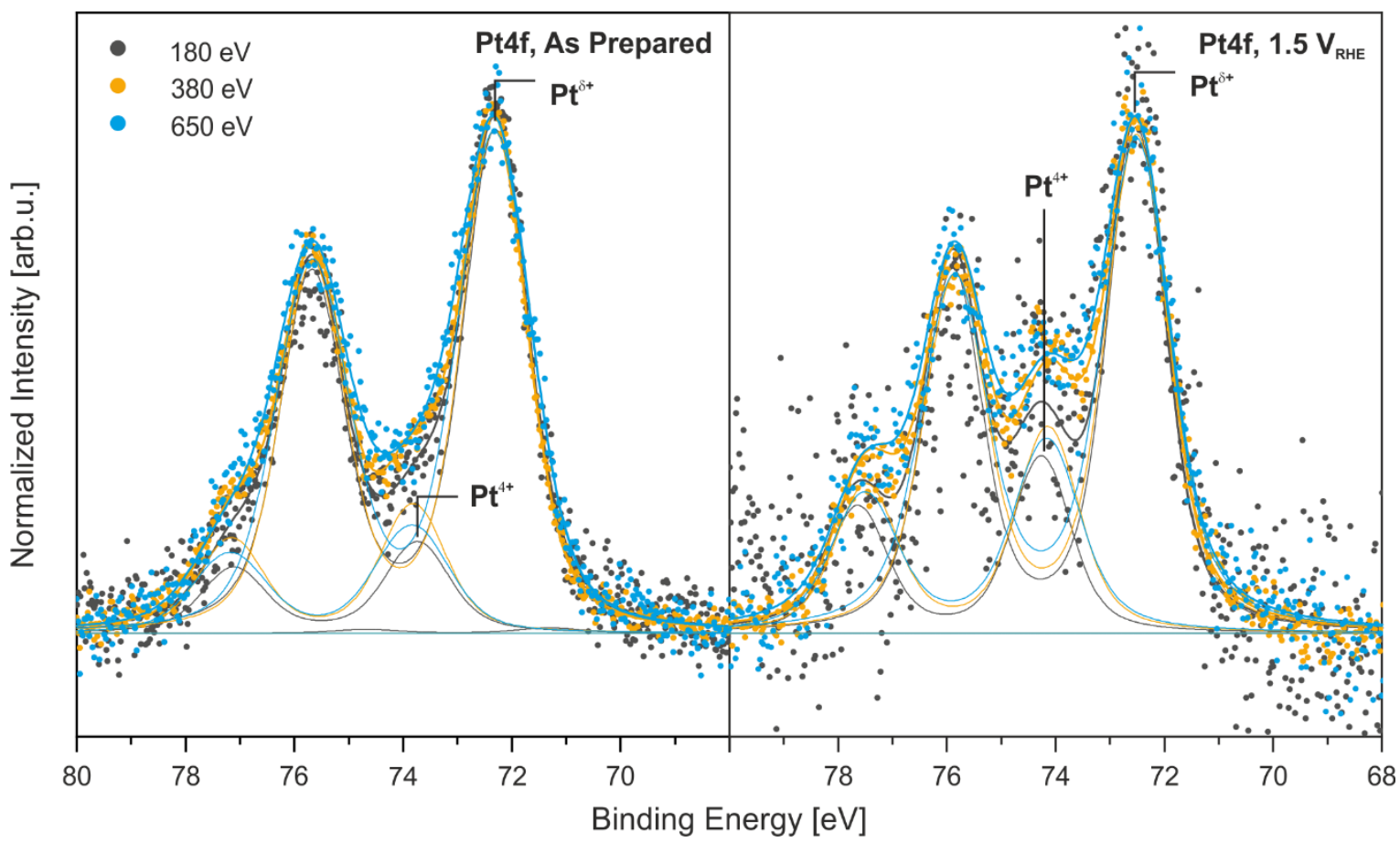

Figure S6 Ratios of $\mathrm{Pt}^{4+}$ to partially oxidized $\mathrm{Pt}^{\delta^{+}}$for subnanometer Pt aggregates (0.14 ML) on $\mathrm{Co}_{3} \mathrm{O}_{4}(111)$ obtained by integration of the fitted $\mathrm{Pt} 4 \mathrm{f}$ core level spectra (a). Comparison of the $\mathrm{Pt} 4 \mathrm{f}$ core level spectra and their respective fits obtained for subnanometer aggregates (0.14 ML) after preparation (left panel) and after EC treatment at $1.5 \mathrm{~V}_{\mathrm{RHE}}$ (b).

\subsection{Total Intensity of the Pt 4f Signal}

While the loss of total intensity in a measurement performed purely in ultrahigh vacuum can indicate NP sintering, ${ }^{11}$ the present study is more complex. Contamination due to electrolyte exposure and dissolution processes need to be considered. The total integrated intensity of all $\mathrm{Pt} 4 \mathrm{f}$ spectra at all excitation energies is plotted in Figure S7. The intensity of the Pt $4 \mathrm{f}$ signal drops significantly after the first exposure to electrolyte. After the following EC treatments, the intensity of the Pt $4 \mathrm{f}$ signal still decreases, but the decrease is weaker than after the first EC treatment. This behavior is expected considering that residues from the electrolyte as well as additional contaminations can cover the sample regardless of the thorough rinsing with 


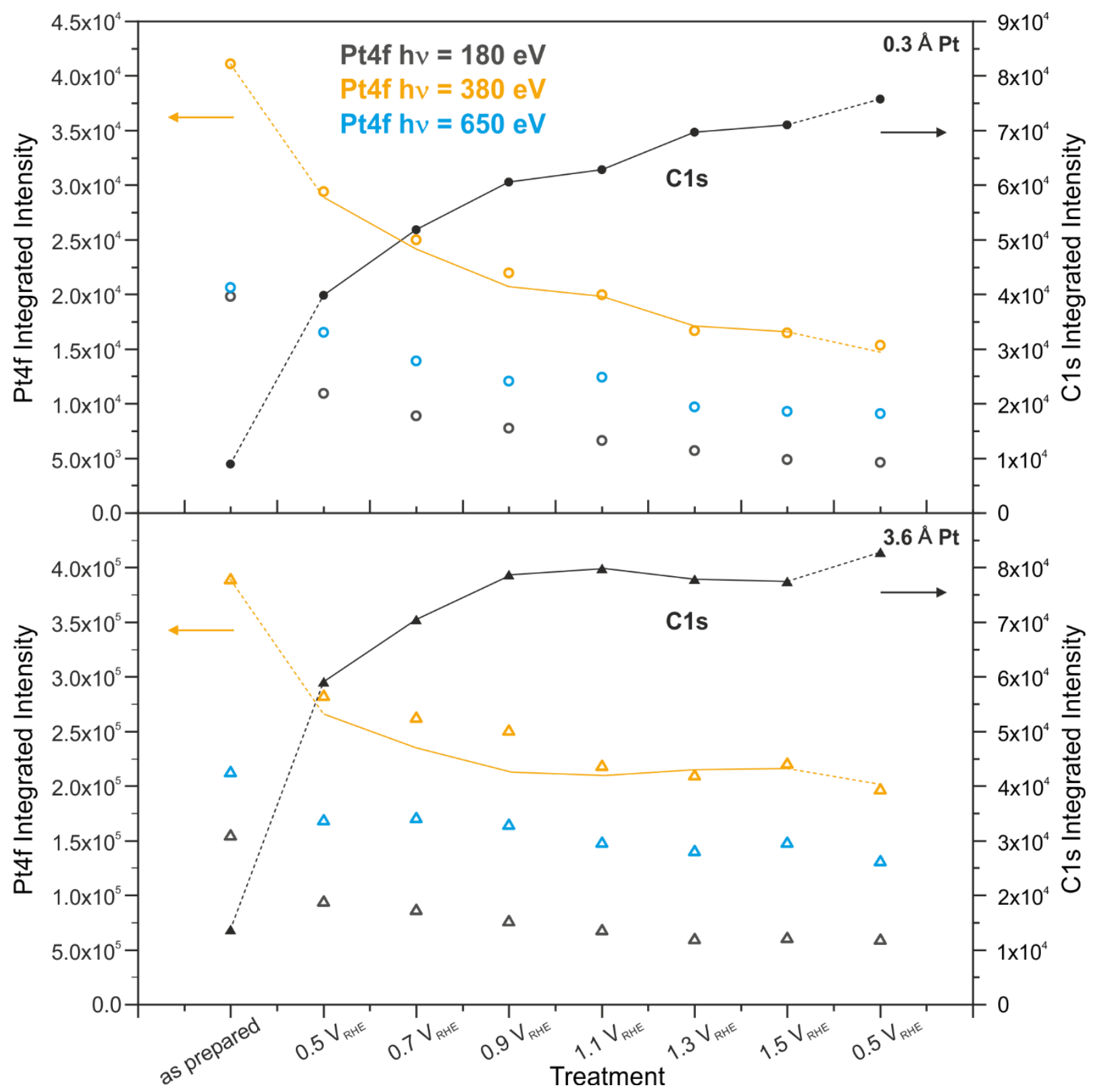

Figure S7 Total integrated intensity of the $\mathrm{Pt} 4 \mathrm{f}$ core level spectra for subnanometer $\mathrm{Pt}$ aggregates (upper panel) and conventional Pt NPs (lower panel) as compared to the integrated intensity of the $\mathrm{C} 1 \mathrm{~s}$ core level spectra $(\mathrm{h} v=380 \mathrm{eV})$. The intensity of the $\mathrm{C} 1 \mathrm{~s}$ signal (black line) was mirrored and scaled to give the orange fit for the Pt $4 \mathrm{f}$ intensity at $380 \mathrm{eV}$.

ultrapure water before transfer to the analysis chamber. ${ }^{15}$ The signal of the buffer, e.g. in the P $2 p$ core level spectra, however, is comparatively low. The strongest signal is observed in the C 1s core level spectra.

The integrated intensity of the C 1s spectra is included in Figure S7. The line following the evolution of the $\mathrm{C} 1 \mathrm{~s}$ signal was copied, mirrored, and scaled to the integrated intensity of the Pt $4 \mathrm{f}$ signal obtained at $380 \mathrm{eV}$. As the Pt 4f signal only deviates slightly from the mirrored $\mathrm{C} 1 \mathrm{~s}$ signal, the damping of the $\mathrm{Pt} 4 \mathrm{f}$ signal is directly coupled to carbonaceous deposits on the 
sample. Carbonaceous deposits most likely stem from contaminations in the UHV buffer chambers during transfer. After the last emersion at $0.5 \mathrm{~V}_{\mathrm{RHE}}$, we estimate the atomic ratio of Pt compared to the amount of carbon. We calculate 1 and $10 \%$ of $\mathrm{Pt}$ for subnanometer and conventional Pt particles and estimate a theoretical carbon layer thickness of 15 and $10 \AA$, respectively. Here, possible contributions to the loss in the signal intensity of Pt $4 \mathrm{f}$ spectra due to Pt dissolution cannot be entirely excluded but are further studied and discussed via online ICP-MS experiments.

\subsection{Oxidation and Reduction of the $\mathrm{Co}_{3} \mathrm{O}_{4}(111)$ Support - Evaluation of Co 2p Core Level}

\section{Spectra and Resonant Photoemission Spectroscopy}

In order to understand how much the oxide support is involved in the EC oxidation of Pt NPs, i.e. to assess the extent of electronic metal-support interactions and oxygen spillover processes, we analyzed the degree of reduction of the $\mathrm{CO}_{3} \mathrm{O}_{4}(111)$ thin film by means of XPS, SRPES, and resonant photoemission spectroscopy (RPES). We recorded Co $2 p$ core level and valence band spectra not only for the $\mathrm{Pt} / \mathrm{Co}_{3} \mathrm{O}_{4}(111)$ samples but also for a $\mathrm{Co}_{3} \mathrm{O}_{4}(111)$ reference sample that was subjected to the same electrochemical measurement protocol (see Materials and Methods). The presence of $\mathrm{Pt}^{4+}$ species after deposition of low amounts of $\mathrm{Pt}$ is striking and, to the best of our knowledge, has not been observed before on $\mathrm{Co}_{3} \mathrm{O}_{4}(111)$. To elucidate the influence of the support, we compare the Co 2 p core level spectra obtained by SRPES and valence band spectra
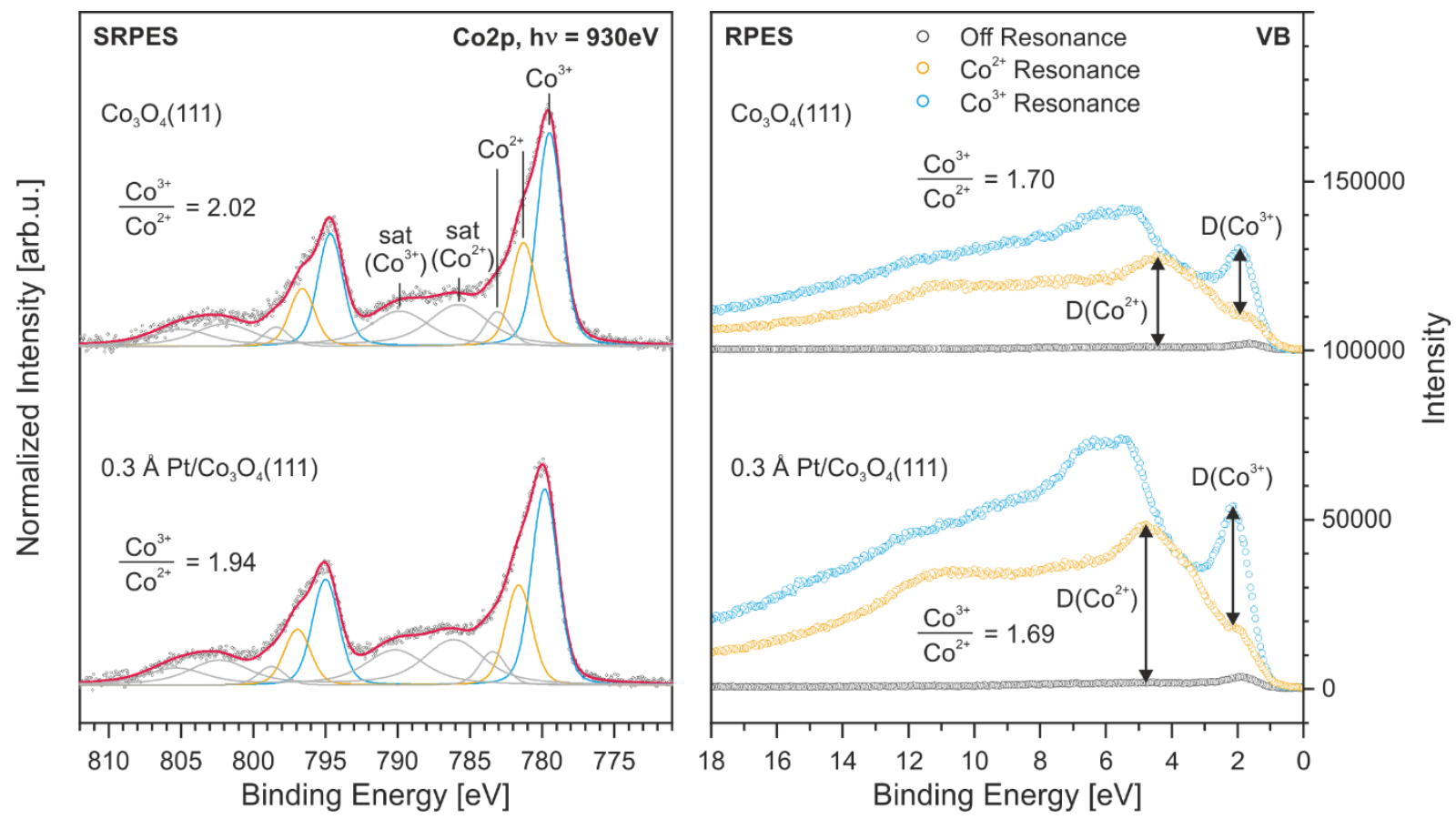

Figure S8 Comparison of the Co $2 p$ core level spectra (left panel) and the valence band spectra (right panel) of the pristine $\mathrm{Co}_{3} \mathrm{O}_{4}(111)$ support (top) and after deposition of subnanometer $\mathrm{Pt}$ aggregates (bottom) to evaluate the degree of reduction of the $\mathrm{Co}_{3} \mathrm{O}_{4}(111)$ film. 
for RPES analysis of the $\mathrm{Co}_{3} \mathrm{O}_{4}(111)$ thin film before and after deposition of $0.3 \AA$ of $\mathrm{Pt}$ (0.14 ML Pt) in Figure S8.

Despite the complexity of the spectral contributions in the Co $2 \mathrm{p}$ core level spectra, it is possible to fit SRPES spectra of $\mathrm{Co}_{3} \mathrm{O}_{4}$ at low degrees of reduction. ${ }^{16}$ The employed fitting procedure has been reported earlier and the degree of reduction is given as the $\mathrm{Co}^{3+} / \mathrm{Co}^{2+}$ ratio obtained from the integrated intensity of the main contributions for $\mathrm{Co}^{3+}$ and $\mathrm{Co}^{2+}$ identified at 779.5 and $781.3 \mathrm{eV}$, respectively. ${ }^{11,16}$

For analysis of the RPES data, we followed a procedure reported earlier. ${ }^{16}$ We chose selected valence band spectra at different photon energies corresponding to the strongest resonances in $\mathrm{Co}^{3+}(\sim 781.0 \mathrm{eV}), \mathrm{Co}^{2+}\left(1.4 \mathrm{eV}\right.$ below the $\mathrm{Co}^{3+}$ resonance $)$, and an off-resonance spectrum $(773.0 \mathrm{eV})$ and determined the resonant enhancement ratio (RER). The RER is given by the $\mathrm{D}\left(\mathrm{Co}^{3+}\right) / \mathrm{D}\left(\mathrm{Co}^{2+}\right)$ ratio, where $\mathrm{D}\left(\mathrm{Co}^{3+}\right)$ corresponds to the difference in intensity of the $\mathrm{Co}^{3+}$ and $\mathrm{Co}^{2+}$ resonance spectra at a binding energy of $\sim 2.0 \mathrm{eV}$ and $\mathrm{D}\left(\mathrm{Co}^{2+}\right)$ is defined as the maximum difference in intensity between the $\mathrm{Co}^{2+}$ and off-resonance spectra between $4-5 \mathrm{eV}$. Employing the reported calibration, the RER yields the $\mathrm{Co}^{3+} / \mathrm{Co}^{2+}$ ratio after multiplication by a factor of 2.2. ${ }^{16}$

After deposition of subnanometer Pt aggregates, the $\mathrm{Co}^{3+} / \mathrm{Co}^{2+}$ ratio is reduced from 2.02 to 1.94 as determined by SRPES or from 1.70 to 1.69 as given by RPES. These values correspond to changes in the $\mathrm{Co}^{3+} / \mathrm{Co}^{2+}$ ratio of 4.2 and $0.6 \%$, respectively. To put these values in relation with the presence of oxidized Pt NPs and the extent of electronic metal-support interactions, we calculate how much the $\mathrm{Co}^{3+} / \mathrm{Co}^{2+}$ ratio should decrease when all $\mathrm{Pt}$ that is present as $\mathrm{Pt}^{4+}$ species would transfer its charge to $\mathrm{Co}^{3+}$ atoms reducing them to $\mathrm{Co}^{2+}$ atoms (see also Table 3 ).

Table 3 Estimation of the $\mathrm{Co}_{3} \mathrm{O}_{4}(111)$ reduction upon charge transfer at $\mathrm{Pt}^{4+}$ formation in $\mathrm{UHV}$.

\begin{tabular}{ccccc}
$\begin{array}{c}\text { Amount of } \\
\text { deposited Pt } \\
{[\mathrm{ML}]}\end{array}$ & $\begin{array}{c}\text { Nominal Pt } \\
\text { thickness }[\AA]\end{array}$ & $\begin{array}{c}\text { Density of Pt } \\
\text { atoms }\left[\mathrm{cm}^{-2}\right]\end{array}$ & $\begin{array}{c}\text { Density of } \mathrm{Pt}^{4+} \\
\text { species }\left[\mathrm{cm}^{-2}\right]\end{array}$ & $\begin{array}{c}\text { Charge per area } \\
{\left[\mathrm{cm}^{-2}\right]}\end{array}$ \\
\hline 0.14 & 0.3 & $7.56 \times 10^{18}$ & $1.55 \times 10^{18}$ & $6.2 \times 10^{18}$ \\
$3 \times \lambda[\AA]$ & $\begin{array}{c}\text { Density of } \\
\mathrm{Co}^{2+} \text { in } \\
3 \times \lambda\left[\mathrm{cm}^{-2}\right]\end{array}$ & $\begin{array}{c}\text { Density of } \\
\mathrm{Co}^{3+} \text { in } 3 \times \lambda \\
{\left[\mathrm{cm}^{-2}\right]}\end{array}$ & $\begin{array}{c}\text { Density of } \mathrm{Co}^{2+} \\
\text { after charge } \\
\text { transfer }\left[\mathrm{cm}^{-2}\right]\end{array}$ & $\begin{array}{c}\text { Density of } \mathrm{Co}^{3+} \\
\text { after charge } \\
\text { transfer }\left[\mathrm{cm}^{-2}\right]\end{array}$ \\
\hline 16.5 & $1.46 \times 10^{20}$ & $2.92 \times 10^{20}$ & $1.52 \times 10^{20}$ & $2.86 \times 10^{20}$
\end{tabular}


First, we calculate the total density of Pt atoms upon depositing a nominal layer of $0.3 \AA$ by taking into account the bulk density of $P t\left(21.45 \mathrm{~g} / \mathrm{cm}^{3}\right)$. The ratio of the integrated peak areas in the $\mathrm{Pt} 4 \mathrm{f}$ core level spectrum after deposition $\left(\mathrm{Pt}^{4+}, 20.5 \%\right)$ gives the density of $\mathrm{Pt}^{4+}$ species per area. The amount of charge that could be transferred to the support is four times as large as the density of $\mathrm{Pt}^{4+}$ species.

Next, we correlate the amount of charge with the reduction of the $\mathrm{Co}_{3} \mathrm{O}_{4}(111)$ thin film. For simplicity, we assume that the information depth of the Co $2 p$ spectra stems from $3 \times \lambda$, the inelastic mean free path of Co $2 p$ photoelectrons $(0.55 \mathrm{~nm})$, and that charge is solely transferred into this region. ${ }^{11}$ Considering the bulk density of $\mathrm{Co}_{3} \mathrm{O}_{4}\left(6.11 \mathrm{~g} / \mathrm{cm}^{3}\right)$ and its stoichiometry we obtain a density of $\mathrm{Co}^{3+}$ or $\mathrm{Co}^{2+}$ atoms per area in the top layer (thickness of $3 \times \lambda$ ). Subtracting the amount of charge per area obtained through formation of $\mathrm{Pt}^{4+}$ species from the $\mathrm{Co}^{3+}$ density and adding it to the $\mathrm{Co}^{2+}$ density gives the new density of $\mathrm{Co}^{3+}$ and $\mathrm{Co}^{2+}$ atoms and the corresponding $\mathrm{Co}^{3+} / \mathrm{Co}^{2+}$ ratio in the reduced oxide film. The new $\mathrm{Co}^{3+} / \mathrm{Co}^{2+}$ ratio of 1.88 corresponds to a change of $6.1 \%$ and neglects further reduction by possible charge transfer from $\mathrm{Pt}$ to $\mathrm{Co}^{3+}$ to form $\mathrm{Pt}^{\delta+}$ or $\mathrm{Pt}^{2+}$ species. If this additional charge transfer was considered,

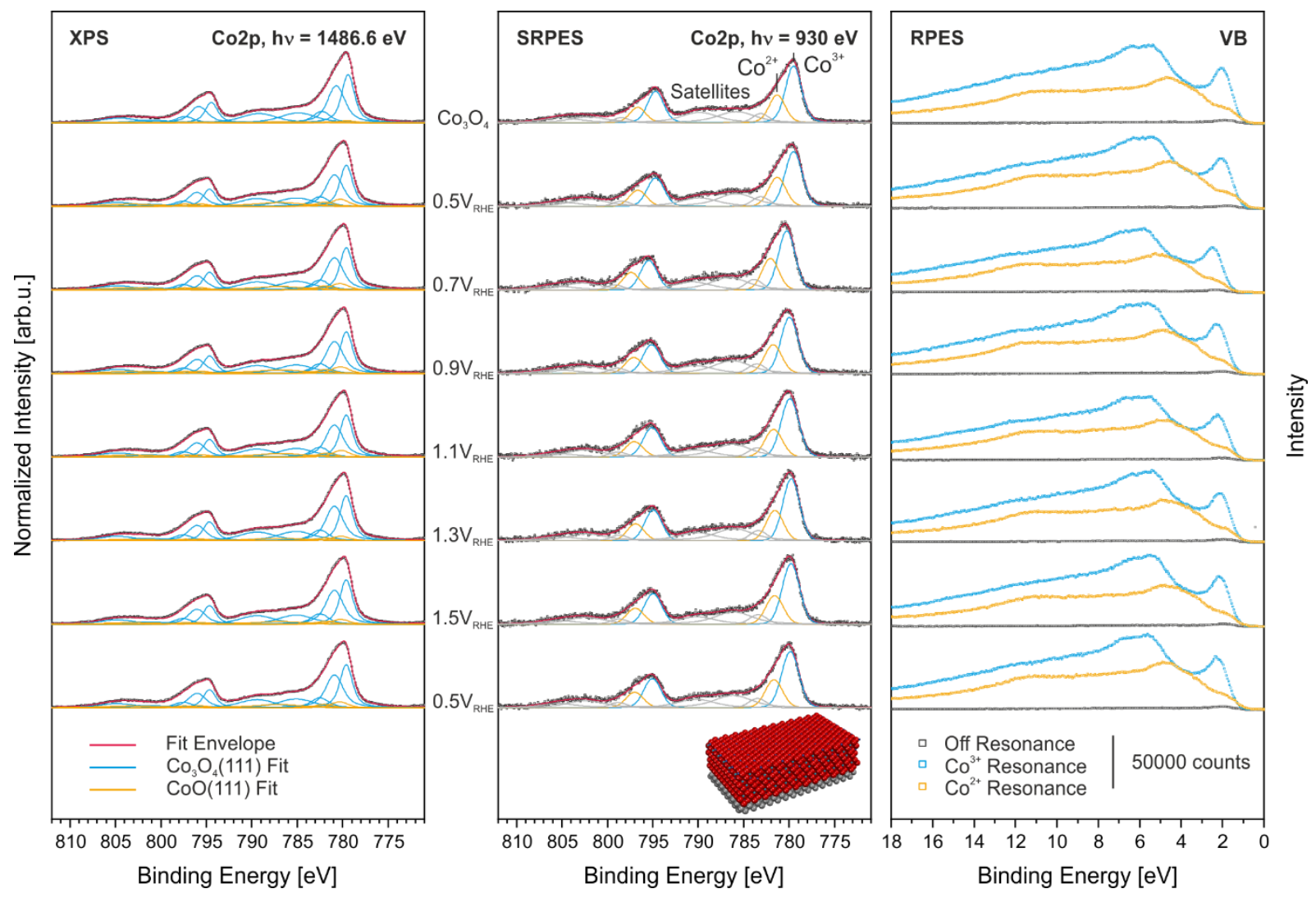

Figure S9 Co 2p core level spectra obtained with an Al Ko source (hv $=1486.6 \mathrm{eV}$, left) and synchrotron radiation $\left(\mathrm{hv}=930 \mathrm{eV}\right.$, middle) and valence band spectra (right) of a $\mathrm{Co}_{3} \mathrm{O}_{4}(111)$ thin film before and after EC treatment in $0.1 \mathrm{M}$ sodium phosphate buffer at $\mathrm{pH}=10$. 


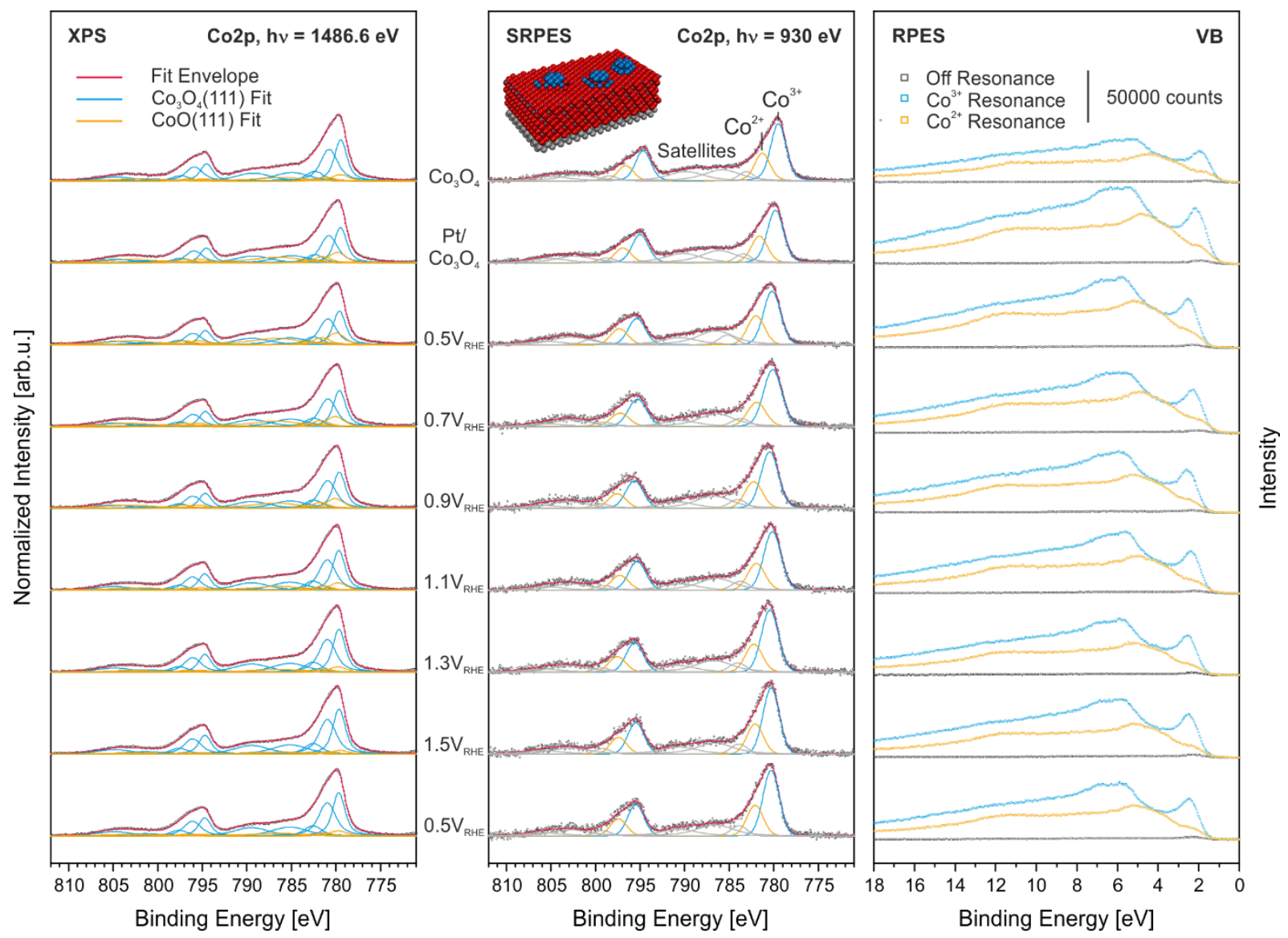

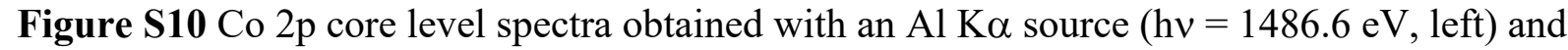
synchrotron radiation $(\mathrm{h} v=930 \mathrm{eV}$, middle) and valence band spectra (right) of subnanometer $\mathrm{Pt}$ aggregates on $\mathrm{Co}_{3} \mathrm{O}_{4}(111)$ thin film before and after Pt deposition and after EC treatment in $0.1 \mathrm{M}$ sodium phosphate buffer at $\mathrm{pH}=10$.

the $\mathrm{Co}^{3+} / \mathrm{Co}^{2+}$ ratio would be even lower and the change greater $\left(\mathrm{Co}^{3+} / \mathrm{Co}^{2+}\right.$ at 1.67 , change of $16.6 \%$ upon additional formation of $79.5 \% \mathrm{Pt}^{2+}$ ). As such a great change in the $\mathrm{Co}^{3+} / \mathrm{Co}^{2+}$ ratio is neither observed in the SRPES nor in the RPES data, it is unlikely that all charge is transferred to the upper support layers only.

In Figure S9 and S10 we provide all Co 2 p core level spectra and valence band spectra obtained for $\mathrm{Co}_{3} \mathrm{O}_{4}(111)$ and $0.3 \AA \mathrm{Pt} / \mathrm{Co}_{3} \mathrm{O}_{4}(111)$ after preparation in UHV and after the EC treatment. The evaluated data is partially summarized in Figure S11. Here, we compare the $\mathrm{Co}^{3+} / \mathrm{Co}^{2+}$ ratio obtained from the analysis of the SPRES and RPES data as described above dependent on the respective sample treatment. The scattering of the data points shows that elucidating the degree of reduction for $\mathrm{Co}_{3} \mathrm{O}_{4}$ is not facile. With the lines in the graph we try to provide a guide-tothe-eye and pinpoint some general trends. Upon immersion at $0.5 \mathrm{~V}_{\mathrm{RHE}}$ the $\mathrm{Co}_{3} \mathrm{O}_{4}(111)$ thin film is slightly reduced. The same behavior is observed for the $\mathrm{Pt} / \mathrm{Co}_{3} \mathrm{O}_{4}(111)$ sample. With increasing potentials $\mathrm{Co}_{3} \mathrm{O}_{4}(111)$ is reoxidized, only to be slightly reduced again upon returning 

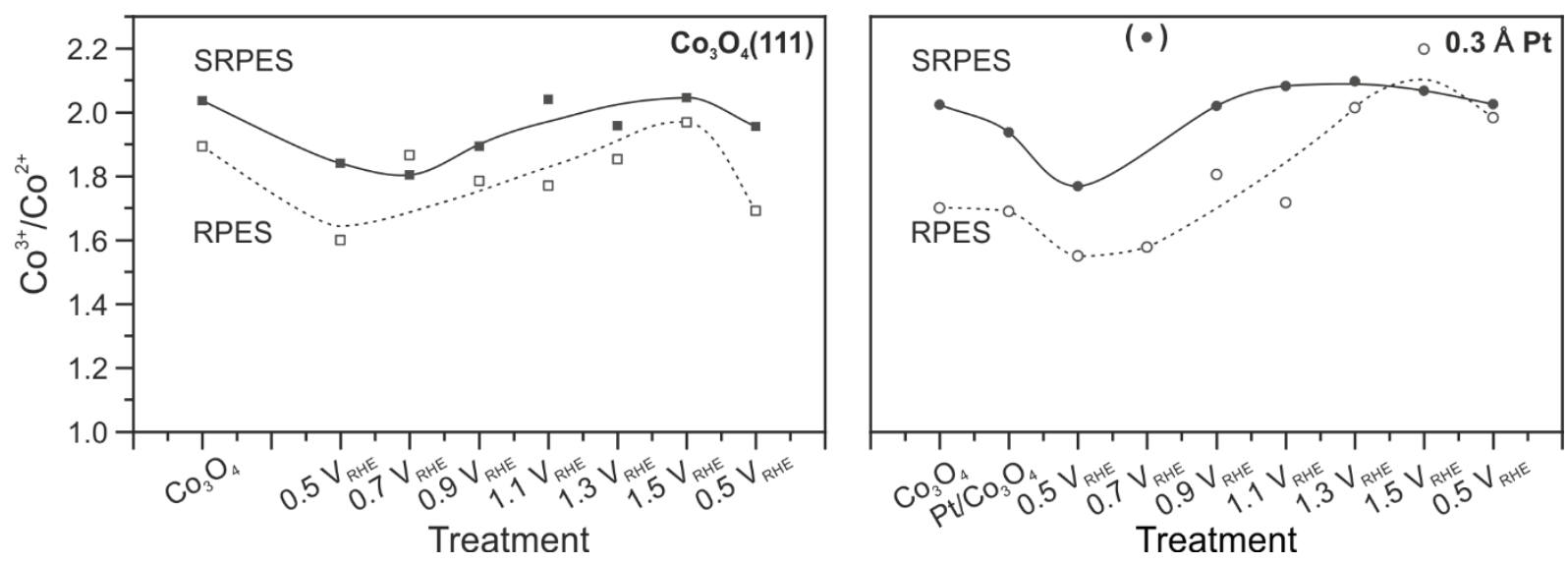

Figure S11 Comparison of the degree of reduction of a $\mathrm{Co}_{3} \mathrm{O}_{4}(111)$ thin film before and after EC treatment without (left) and with subnanometer Pt particles deposited on (right).

to the initial potential of $0.5 \mathrm{~V}_{\text {RHE}}$. The $\mathrm{Co}_{3} \mathrm{O}_{4}$ support itself is dynamically oxidized and reduced under potential control. The $\mathrm{Pt} / \mathrm{Co}_{3} \mathrm{O}_{4}(111)$ sample follows the same trends. Hence, it is not easy to relate changes in the $\mathrm{Co}^{3+} / \mathrm{Co}^{2+}$ ratio to charge transfer or oxygen spillover processes between subnanometer Pt aggregates and the support, when oxygen can also be supplied by the electrolyte and interacts with the support in the same potential window.

\subsection{EC Data}

While exposing the samples to the electrolyte under potential control, we also recorded the current response to exclude substantial errors stemming from the EC treatment. The data are

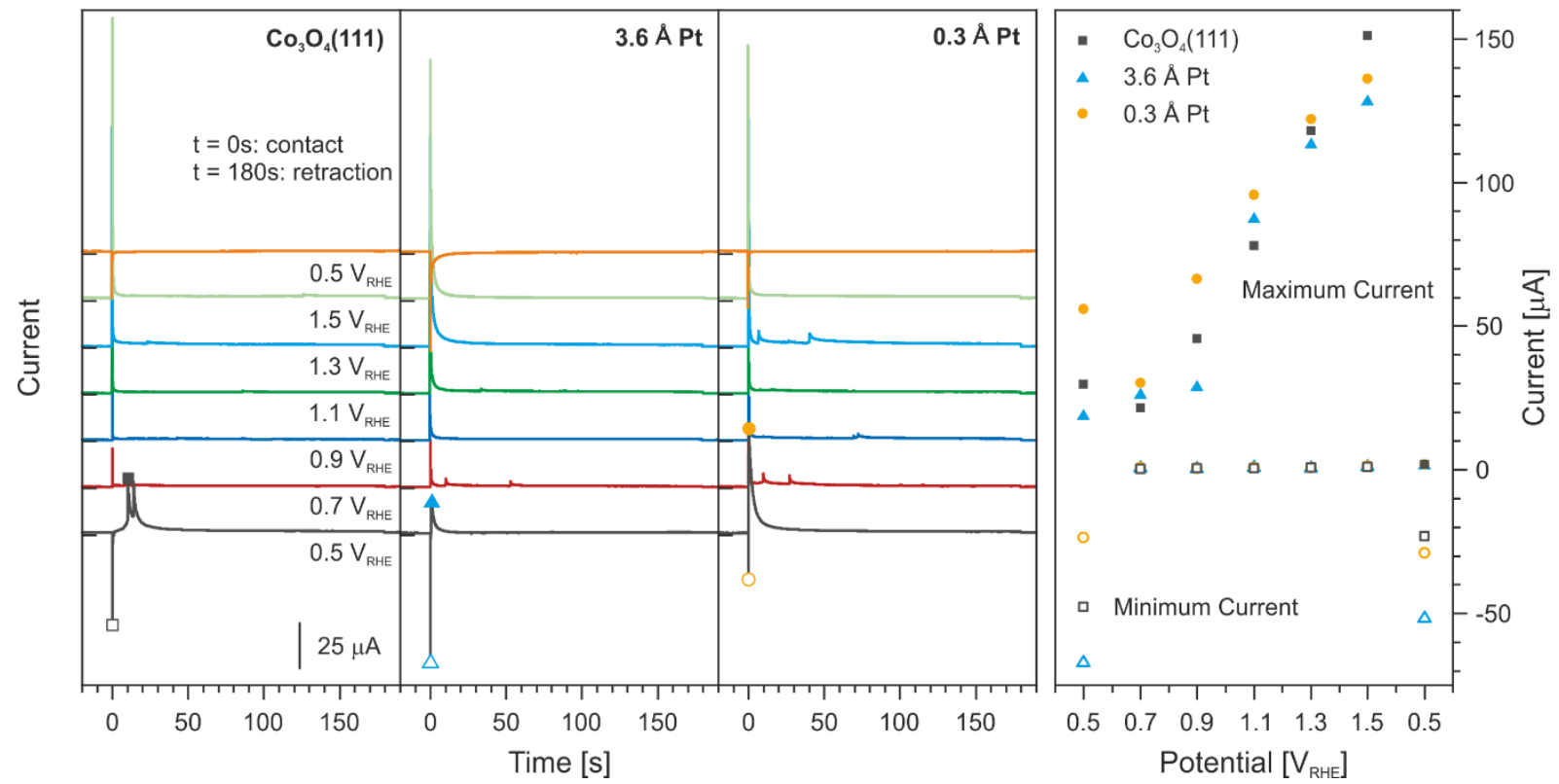

Figure S12 Current responses of $\mathrm{Co}_{3} \mathrm{O}_{4}(111)$, conventional Pt NPs on $\mathrm{Co}_{3} \mathrm{O}_{4}(111)$, and subnanometer $\mathrm{Pt}$ aggregates on $\mathrm{Co}_{3} \mathrm{O}_{4}(111)$ during exposure to $0.1 \mathrm{M}$ sodium phosphate buffer $(\mathrm{pH}=10)$ at constant potential. In the right panel the minimum (hollow symbols) and maximum (full symbols) respective peak currents are shown. 
presented in Figure S12. Small current spikes are attributed to short disruptions, e.g. movement close to the experimental setup.

At $0.5 \mathrm{~V}_{\mathrm{RHE}}$ negative, reductive currents are recorded. Starting from $0.7 \mathrm{~V}_{\mathrm{RHE}}$ only positive, increasingly oxidative currents are observed. These current responses corroborate the photoelectron spectroscopic results on the oxidation state of the metal oxide support film, which is reduced at $0.5 \mathrm{~V}_{\mathrm{RHE}}$ and reoxidized at increasing potentials. Comparing the three samples, strong deviations in the current flow are only observed at the lowest potential. 


\section{Current Responses and Potential-Dependent Evaluation of the online ICP-MS}

\section{Measurements}

In this section we provide complementary data on the current that was recorded during the online ICP-MS measurements, see Figure S13. Additionally, Figure S13 again contains the dissolution rates for $\mathrm{Pt}$ (middle) and Co (bottom) in a direct comparison of the samples and employing different scales.

In the first experiment that mimics the experimental procedure of the ex situ emersion SRPES, a negative, cathodic current is recorded for all three samples upon contact at $0.5 \mathrm{~V}_{\mathrm{RHE}}$. Stepping the potential up then results in positive, anodic currents. This behavior fits well to the current response obtained in ex situ emersion SRPES. The only difference is observed in the cathodic current at 0.5 and $0.7 \mathrm{~V}_{\mathrm{RHE}}$ which is strongly enhanced in the online ICP-MS measurement for conventional NPs. Similar increased cathodic currents are also recorded during the CV procedure for conventional NPs below $0.9 \mathrm{~V}_{\mathrm{RHE}}$. This behavior is attributed to the oxygen
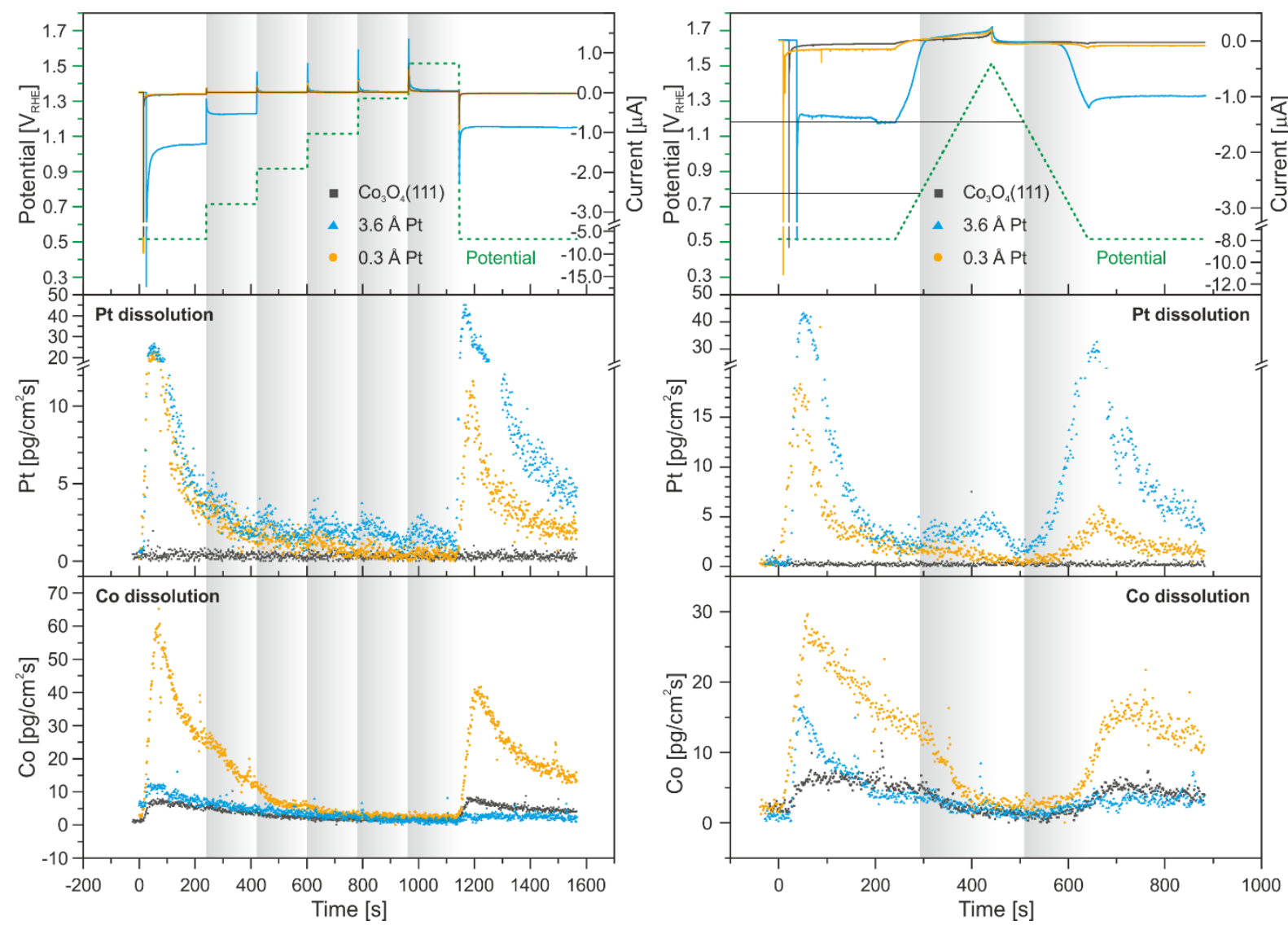

Figure S13 Complementary online ICP-MS data for the step potential procedure (left) and the $\mathrm{CV}$ measurement (right) in $0.05 \mathrm{M}$ sodium phosphate buffer at $\mathrm{pH}=10$. Current responses are shown in the top panel. The Pt dissolution rate is presented in the middle and the Co dissolution rate in the bottom. The results for $\mathrm{Co}_{3} \mathrm{O}_{4}(111)$ are marked in black, conventional Pt NPs on $\mathrm{Co}_{3} \mathrm{O}_{4}(111)$ in blue, and subnanometer Pt aggregates on $\mathrm{Co}_{3} \mathrm{O}_{4}(111)$ in orange. 
reduction reaction at $\mathrm{Pt}$ which is typically reported to start below $0.9 \mathrm{~V} \mathrm{RHE} .{ }^{17}$ Note that small leakages could not be avoided while performing the online ICP-MS experiments for conventional NPs due to a slight curvature of the $\operatorname{Ir}(100)$ single crystal. Consequently, the presence of oxygen is not surprising and could not be avoided completely.

When the potential is increased during the step protocol dissolution of $\mathrm{Pt}$ is observed as small peak at $0.9 \mathrm{~V}_{\mathrm{RHE}}$ and above at every consecutive step for conventional NPs on $\mathrm{Co}_{3} \mathrm{O}_{4}(111)$. In the $\mathrm{CV}$, two anodic peaks are recorded indicating the dissolution of $\mathrm{Pt}$ at conventional NPs. Here, dissolution starts roughly at $0.8 \mathrm{~V}_{\mathrm{RHE}}$ and increases again at $1.1 \mathrm{~V}_{\mathrm{RHE}}$. These values are in fair agreement with literature and are attributed to the transient dissolution of Pt during the formation of $\mathrm{PtO}$ and $\mathrm{PtO}_{2}$ in alkaline media, respectively. ${ }^{18-19}$ Further contributions to the second anodic peak can stem from surface processes and changes in the oxidation state during the onset of the oxygen evolution reaction. ${ }^{18}$

Anodic dissolution of $\mathrm{Pt}$ is not observed for subnanometer aggregates. On the contrary, the dissolution rate of Pt only levels off completely above $1.1 \mathrm{~V}_{\mathrm{RHE}}$ in the case of subnanometer NPs. A similar behavior is observed for the Co dissolution. Whereas cobalt dissolution is negligible during the step protocol on $\mathrm{Co}_{3} \mathrm{O}_{4}(111)$ and for conventional NPs on $\mathrm{Co}_{3} \mathrm{O}_{4}(111)$, enhanced cobalt dissolution only completely stops at $1.1 \mathrm{~V}_{\mathrm{RHE}}$ for subnanometer aggregates. During the $\mathrm{CV}$, the drop in the Co dissolution rate coincides on all samples at $0.8-0.9 \mathrm{~V}_{\mathrm{RHE}}$ during the anodic scan but is most pronounced for subnanometer aggregates.

The CV data is analyzed in more detail in Figure S14. Here, we plot the current and dissolution rate dependent on the potential with a special emphasis on the dissolution during the reverse, cathodic scan. Note that in the right panel adjacent data points were averaged to reduce the amount of noise in the dissolution data. It is noteworthy that the cathodic dissolution of Pt starts at $1.1 \mathrm{~V}_{\mathrm{RHE}}$ irrespective of the NP size. Cathodic dissolution is attributed to the reduction of platinum oxide and results from place-exchange processes. ${ }^{20}$ When we compare the Co dissolution during the cathodic scan, we observe the following. On the pristine $\mathrm{Co}_{3} \mathrm{O}_{4}(111)$ support and for conventional NPs Co dissolution starts at $0.9 \mathrm{~V}_{\mathrm{RHE}}$ and increases linearly. For subnanometer NPs, on the other hand, the dissolution rate of Co increases earlier $\left(\sim 1.1 \mathrm{~V}_{\mathrm{RHE}}\right)$ and more rapidly and closely resembles the dissolution curve of Pt. 

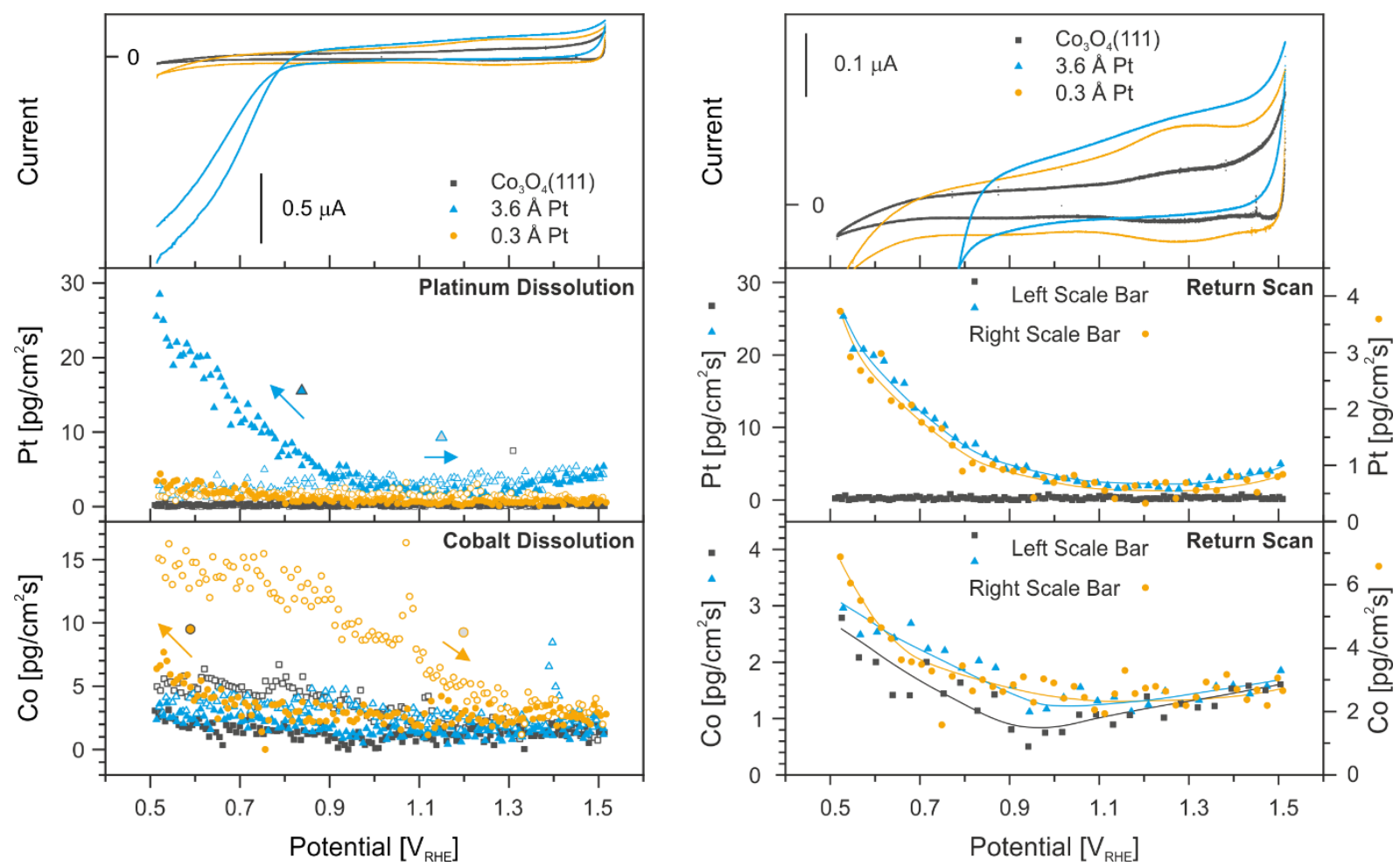

Figure S14 Potential-dependent representation of the CV measurements obtained with the online ICP-MS. Current response (top), Pt dissolution (middle), and Co dissolution (bottom) for $\mathrm{Co}_{3} \mathrm{O}_{4}(111)$ (black), conventional Pt NPs on $\mathrm{Co}_{3} \mathrm{O}_{4}(111)$ (blue), and subnanometer Pt aggregates on $\mathrm{Co}_{3} \mathrm{O}_{4}(111)$ (orange). In the left panel, the complete data is shown, while the right panel contains a zoom of the $\mathrm{CV}$ and the return-scan for the dissolution data.

While stepping up the potential, as well as during the cathodic potential scan, the dissolution rates of Pt and Co behave similarly in the case of subnanometer NPs. Hence, we conclude that both processes are related. The results are connected to the ex situ emersion SRPES results in the main letter and discussed therein.

In a last note we comment on the CV obtained during the online ICP-MS experiments. For the pristine $\mathrm{Co}_{3} \mathrm{O}_{4}(111)$ support we observe a broad peak at $1.3 \mathrm{~V}_{\mathrm{RHE}}$ both, in the anodic and cathodic scan. This peak is attributed to the oxidation of $\mathrm{Co}_{3} \mathrm{O}_{4}$ spinel to $\mathrm{CoOOH}$ and in line with literature where Reikowski et al. reported the reversible formation of a $\mathrm{CoOOH}$ skin layer on $\mathrm{Co}_{3} \mathrm{O}_{4} / \mathrm{Au}(111) .{ }^{21}$ For subnanometer Pt aggregates this peak is strongly enhanced indicating an increased redox activity. 


\section{References}

(1) Biedermann, K.; Gubo, M.; Hammer, L.; Heinz, K. Phases and Phase Transitions of Hexagonal Cobalt Oxide Films on $\operatorname{Ir}(100)-(1$ x 1). J. Phys.: Condens. Matter 2009, 21, 185003.

(2) Meyer, W.; Biedermann, K.; Gubo, M.; Hammer, L.; Heinz, K. Surface Structure of Polar $\mathrm{Co}_{3} \mathrm{O}_{4}(111)$ Films Grown Epitaxially on $\operatorname{Ir}(100)-(1$ x 1). J. Phys.: Condens. Matter 2008, $20,265011$.

(3) Libra, J. KolXPD: Spectroscopy Data Measurement and Processing, kolibrik.net.

(4) Faisal, F.; Bertram, M.; Stumm, C.; Waidhas, F.; Brummel, O.; Libuda, J. Preparation of Complex Model Electrocatalysts in Ultra-High Vacuum and Transfer Into the Electrolyte for Electrochemical IR Spectroscopy and Other Techniques. Rev. Sci. Instrum. 2018, 89, 114101.

(5) Faisal, F.; Stumm, C.; Bertram, M.; Waidhas, F.; Lykhach, Y.; Cherevko, S.; Xiang, F. F.; Ammom, M.; Vorokhta, M.; Šmid, B.; Skála, T.; Tsud, N.; Neitzel, A.; Beranová, K.; Prince, K. C.; Geiger, S.; Kasian, O.; Wähler, T.; Schuster, R.; Schneider, M. A.; Matolín, V.; Mayrhofer, K. J. J.; Brummel, O.; Libuda, J. Electrifying Model Catalysts for Understanding Electrocatalytic Reactions in Liquid Electrolytes. Nat. Mater. 2018, 17, 592-598.

(6) Klemm, S. O.; Topalov, A. A.; Laska, C. A.; Mayrhofer, K. J. J. Coupling of a High Throughput Microelectrochemical Cell with Online Multielemental Trace Analysis by ICPMS. Electrochem. Commun. 2011, 13, 1533-1535.

(7) Schuppert, A. K.; Topalov, A. A.; Katsounaros, I.; Klemm, S. O.; Mayrhofer, K. J. J. A Scanning Flow Cell System for Fully Automated Screening of Electrocatalyst Materials. J. Electrochem. Soc. 2012, 159, F670-F675.

(8) Bertram, M.; Waidhas, F.; Jevric, M.; Fromm, L.; Schuschke, C.; Kastenmeier, M.; Görling, A.; Moth-Poulsen, K.; Brummel, O.; Libuda, J. Norbornadiene Photoswitches Anchored to Well-Defined Oxide Surfaces: From Ultrahigh Vacuum Into the Liquid and the Electrochemical Environment. J. Chem. Phys. 2020, 152, 044708.

(9) Ferstl, P.; Mehl, S.; Arman, M. A.; Schuler, M.; Toghan, A.; Laszlo, B.; Lykhach, Y.; Brummel, O.; Lundgren, E.; Knudsen, J.; Hammer, L.; Schneider, M. A.; Libuda, J. Adsorption and Activation of $\mathrm{CO}$ on $\mathrm{Co}_{3} \mathrm{O}_{4}(111)$ Thin Films. J. Phys. Chem. C 2015, 119, 16688-16699.

(10) Faisal, F.; Bertram, M.; Stumm, C.; Wähler, T.; Schuster, R.; Lykhach, Y.; Neitzel, A.; Skála, T.; Tsud, N.; Beranová, K.; Prince, K. C.; Matolín, V.; Brummel, O.; Libuda, J. Electrocatalysis with Atomically Defined Model Systems: Metal-Support Interactions Between Pt Nanoparticles and $\mathrm{Co}_{3} \mathrm{O}_{4}(111)$ Under Ultrahigh Vacuum and in Liquid Electrolytes. J. Phys. Chem. C 2018, 122, 20787-20799. 
(11) Lykhach, Y.; Faisal, F.; Skála, T.; Neitzel, A.; Tsud, N.; Vorokhta, M.; Dvořák, F.; Beranová, K.; Kosto, Y.; Prince, K. C.; Matolin, V.; Libuda, J. Interplay Between the MetalSupport Interaction and Stability in $\mathrm{Pt} / \mathrm{Co}_{3} \mathrm{O}_{4}(111)$ Model Catalysts. J. Mater. Chem. A 2018, 6, 23078-23086.

(12) Tanuma, S.; Powell, C. J.; Penn, D. R. Calculations of Electron Inelastic Mean Free Paths. V. Data for 14 Organic Compounds over the 50-2000 eV Range. Surf. Interface Anal. 1994, 21, 165-176.

(13) Favaro, M.; Valero-Vidal, C.; Eichhorn, J.; Toma, F. M.; Ross, P. N.; Yano, J.; Liu, Z.; Crumlin, E. J. Elucidating the Alkaline Oxygen Evolution Reaction Mechanism on Platinum. J. Mater. Chem. A 2017, 5, 11634-11643.

(14) Imai, H.; Izumi, K.; Matsumoto, M.; Kubo, Y.; Kato, K.; Imai, Y. In Situ and Real-Time Monitoring of Oxide Growth in a Few Monolayers at Surfaces of Platinum Nanoparticles in Aqueous Media. J. Am. Chem. Soc. 2009, 131, 6293-6300.

(15) Brummel, O.; Lykhach, Y.; Vorokhta, M.; Šmíd, B.; Stumm, C.; Faisal, F.; Skála, T.; Tsud, N.; Neitzel, A.; Beranová, K.; Prince, K. C.; Matolín, V.; Libuda, J. Redox Behavior of $\mathrm{Pt} / \mathrm{Co}_{3} \mathrm{O}_{4}(111)$ Model Electrocatalyst Studied by X-ray Photoelectron Spectroscopy Coupled with an Electrochemical Cell. J. Phys. Chem. C 2019, 123, 8746-8758.

(16) Lykhach, Y.; Piccinin, S.; Skála, T.; Bertram, M.; Tsud, N.; Brummel, O.; Camellone, M. F.; Beranová, K.; Neitzel, A.; Fabris, S.; Prince, K. C.; Matolín, V.; Libuda, J. Quantitative Analysis of the Oxidation State of Cobalt Oxides by Resonant Photoemission Spectroscopy. $J$. Phys. Chem. Lett. 2019, 10, 6129-6136.

(17) Drnec, J.; Ruge, M.; Reikowski, F.; Rahn, B.; Carlà, F.; Felici, R.; Stettner, J.; Magnussen, O. M.; Harrington, D. A. Pt Oxide and Oxygen Reduction at Pt(111) Studied by Surface X-ray Diffraction. Electrochem. Commun. 2017, 84, 50-52.

(18) Cherevko, S.; Zeradjanin, A. R.; Keeley, G. P.; Mayrhofer, K. J. J. A Comparative Study on Gold and Platinum Dissolution in Acidic and Alkaline Media. J. Electrochem. Soc. 2014, 161, H822-H830.

(19) Schalenbach, M.; Kasian, O.; Ledendecker, M.; Speck, F.; Mingers, A.; Mayrhofer, K.; Cherevko, S. The Electrochemical Dissolution of Noble Metals in Alkaline Media. Electrocatalysis 2018, 9, 153-161.

(20) Topalov, A. A.; Cherevko, S.; Zeradjanin, A. R.; Meier, J. C.; Katsounaros, I.; Mayrhofer, K. J. J. Towards a Comprehensive Understanding of Platinum Dissolution in Acidic Media. Chem. Sci. 2014, 5, 631-638. 
(21) Reikowski, F.; Maroun, F.; Pacheco, I.; Wiegmann, T.; Allongue, P.; Stettner, J.; Magnussen, O. M. Operando Surface X-ray Diffraction Studies of Structurally Defined $\mathrm{Co}_{3} \mathrm{O}_{4}$ and $\mathrm{CoOOH}$ Thin Films during Oxygen Evolution. ACS Catal. 2019, 9, 3811-3821. 